\title{
Seismic Behavior of RNC-Isolated Bridges: A Comparative Study under Near-Fault, Long-Period, and Pulse-Like Ground Motions
}

\author{
Mohammed Ismail, ${ }^{1,2,3}$ José Rodellar, $^{4}$ and Joan R. Casas ${ }^{5}$ \\ ${ }^{1}$ SENER Ingeniería y Sistemas, 08290 Barcelona, Spain \\ ${ }^{2}$ Structural Engineering Department, Zagazig University, Zagazig 44519, Egypt \\ ${ }^{3}$ Universitat Politècnica de Catalunya-BarcelonaTECH, 08034 Barcelona, Spain \\ ${ }^{4}$ Applied Mathematics III Department, Universitat Politècnica de Catalunya, 08034 Barcelona, Spain \\ ${ }^{5}$ Construction Engineering Department, Universitat Politècnica de Catalunya, 08034 Barcelona, Spain \\ Correspondence should be addressed to Joan R. Casas; joan.ramon.casas@upc.edu
}

Received 22 August 2015; Revised 14 December 2015; Accepted 20 December 2015

Academic Editor: Francisco J. Molina

Copyright (C) 2016 Mohammed Ismail et al. This is an open access article distributed under the Creative Commons Attribution License, which permits unrestricted use, distribution, and reproduction in any medium, provided the original work is properly cited.

\begin{abstract}
This paper introduces a recent seismic isolation system, named Roll-in-Cage (RNC) isolator, for efficient protection of bridges against destructive earthquakes. The RNC isolator is a rolling-based isolation system with several integrated features in a single unit providing all the necessary functions of vertical rigid support, horizontal flexibility, full stability, hysteretic energy dissipation, and resistance to minor vibration loads. Besides, it is distinguished by a self-stopping (buffer) mechanism to limit the peak bearing displacement under abrupt severe excitations, a linear gravity-based self-recentering mechanism to prevent permanent dislocations after excitations, and a notable resistance to axial tension. A three-span box-girder prestressed concrete bridge is investigated under a set of different destructive real and synthetic earthquakes including near-fault, long-period, and pulse-like ground motions. As a performance measure, the responses of isolated and nonisolated cases are compared. In addition, the RNC isolator's behavior is then compared with those of other isolation systems including HDB, FPS, and LRB. The results confirmed that the RNC isolator has a superior behavior in achieving a balance between the peak displacements and accelerations of the isolated deck, relative other isolation systems, besides being the most (relatively) efficient isolator in the great majority of studies performed.
\end{abstract}

\section{Introduction}

Seismic isolation is the separation of the structure from the harmful motions of the ground by providing flexibility and energy dissipation capability through the insertion of the socalled isolators between the foundation and the superstructure. It is not a long time since the first application of the isolators as the first base-isolated building in the USA was built in 1985 [1], although the idea is more than a century years old.

A century ago, in Japan, a small wooden house was built on ball bearings [2], while another building was base-isolated by means of several layers of timber logs in the longitudinal and transverse direction [3]. In 1906, an isolation system in which a building is placed on a rigid plate, supported on spherical bodies of hard material, was proposed by Buckle and Mayes [4]. In 1909, in England, another system by Kelly [5] was designed to separate a building from its foundation using a layer of sand or talc. The Imperial Hotel in Tokyo, constructed in 1921, was founded on an $8 \mathrm{ft}$ thick layer of firm soil under which there is a 60 to $70 \mathrm{ft}$ thick layer of soft mud. The soft mud acted as isolation system and the building survived the devastating 1923 Tokyo earthquake $[4,5]$.

The concept of soft stories was introduced in the 1930s to protect the upper floors of multistory buildings. The idea was by designing very flexible first-story columns, as soft supports, to provide energy absorption through columns yield. However, yielded columns have greatly reduced buckling load, proving the concept to be impractical [6]. To overcome the inherent dangers of soft supports, many types of roller-bearing systems have been proposed. This type of bearings offers incomparable structure-foundation 
decoupling. However, they are very low in damping and have no inherent resistance to lateral load, and therefore some other supplementary mechanisms are needed in parallel, to provide wind resistance and energy-absorbing capacity [7].

Parallel to such development, the flexibility of natural rubber was also seen as another solution for increasing the system flexibility. In 1968, a reinforced concrete building was founded on 54 hard rubber blocks in Macedonia. These rubber blocks are unreinforced and bulge sideways under the weight of this concrete structure. Owing to having the same stiffness of the isolation system in all directions, the building bounces and rocks back and forth $[8,9]$. The subsequent development of plain elastomeric bearings, to make the vertical stiffness times the horizontal stiffness, has made base isolation a practical reality. However, these plain elastomeric bearings lack hysteretic damping and efficient mechanical recentering mechanisms. Later, a large number of isolation devices were developed, and now base isolation has reached the stage of gaining acceptance and replacing the conventional construction, at least for important structures.

The lead rubber bearing (LRB) was invented in the 1970s [10-12], and this allowed flexibility and damping to be included in a single unit. In the early 1980s developments in rubber technology lead to new rubber compounds which were termed high damping rubber (HDR) [13]. However, both LRB and HDR isolation systems still lack buffer, effective recentering mechanism, and aptitude for low-mass structures. In addition, both LRB and HDR undergo increasing reduction in their bearing areas when being displaced laterally. Such bearing area reduction imposes severe limitation on the height/width and deformation/height ratios of those two types of bearings.

An alternative way to enhance damping mechanism of isolation system is to take the advantage of friction-based isolation bearings in which a sliding surface is used to incorporate isolation and energy dissipation in one unit [14]. In 1986, an isolation system, namely, the friction pendulum system (FPS), was introduced by Al-Hussaini et al. [15]. The FPS uses friction to dissipate the transmitted energy to the structure and provides restoring mechanism by gravity. Principally, a building supported on FPS isolators exhibits uplift and behaves as a simple pendulum having a constant vibration period, which represents a severe practical difficulty [16]. Another drawback is the increase of the sliding friction coefficient as sliding velocity increases (a characteristic of Teflon, the interface liner).

Rolling-based bearings offer the maximum structureground decoupling, but they lack damping, buffer, and recentering mechanisms as in Jangid [17], Lin and Hone [18], and Lin et al. [19]. Jangid and Londhe [20] benefited from the elliptical shape of rollers to ensure a gravity-based recentering mechanism. However, this shape caused vertical structural uplift during horizontal rolling and is unable to prevent permanent dislocations under strong earthquakes due to the absence of an accompanying self-stopping mechanism. To overcome this difficulty, spherical rollers inside two opposite concave plates were proposed in Zhou et al. [21] as a rollingpendulum system. This provided a gravity-based restoring

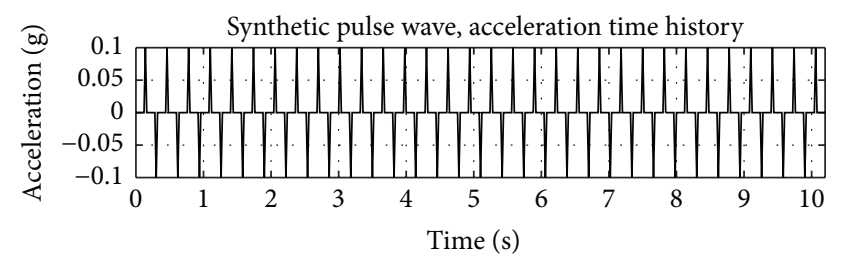

FIGURE 1: Acceleration time history of the selected pulse wave.

force without permanent displacement but damping was still missing and structural uplift was exhibited.

So far, the existing isolation systems are based on well known and accepted physical principles but are still having some functional drawbacks. Therefore, the Roll-in-Cage (RNC) isolator has been proposed by Ismail [22] to incorporate the incomparable structure-foundation decoupling offered by rolling-bearings, the vertical stiffness of elastomeric bearings, the efficient restoring mechanism provided by FPS, and the efficient damping of FPS, LRB, and HDR besides some additional necessary features such as buffer (or self-stopping mechanism under severe abrupt excitations) and notable axial tension-resistance mechanisms. The Rollin-Cage (RNC) isolator by Ismail [22] and Ismail et al. [23] was numerically characterized in Ismail et al. [24]. Then, it was numerically investigated under real and synthetic excitations considering variety of isolated systems ranging from motion-sensitive equipment $[25,26]$ to huge building structures [27-30]. Recently, the device has been characterized experimentally [31].

In this paper, the RNC isolator is presented as an alternative isolation bearing for efficient protection of common highway bridge structures. A three-span box-girder prestressed concrete bridge is investigated under a set of different destructive real and synthetic earthquakes including near-fault, long-period, and pulse-like ground motions. The responses of isolated and nonisolated cases are compared as a performance or efficiency measure. In addition, the RNC isolator's behaviors are then compared with those of other commonly used isolation systems at present including LRB, HDR, and FPS. The RNC isolator was numerically implemented and investigated into modern long-span cablestayed bridges in Ismail and Casas [32], and now it is the time to compare its behavior to more common and traditional bridge structures of short-medium spans, considering practical structural design issues.

\section{Ground Motions}

A set of eleven recorded and one synthetic ground motions is used in this study, including near-fault, long-period, and pulse-like earthquakes, in addition to a synthetic pulse wave shown in Figure 1. Table 1 lists those twelve ground motions. Throughout this paper, each ground motion is distinguished by its corresponding number in Table 1 . The ground motions from 1 to 10 in Table 1 are all near-fault earthquakes characterized by high displacement and velocity pulses. In addition to the Mexico City earthquake, those near-fault records include a ground motion having a reasonably long predominant 
TABLE 1: Ground motions of the present study. The NF stands for near-fault ground motion.

\begin{tabular}{|c|c|c|c|c|c|c|c|}
\hline \multirow{2}{*}{ Number } & \multicolumn{3}{|c|}{ Ground motion } & \multirow{2}{*}{ Number } & \multicolumn{3}{|c|}{ Ground motion } \\
\hline & Name & Location & Year & & Name & Location & Year \\
\hline 1 & Chi-Chi (NF) & Taiwan & 1999 & 2 & Friuli (NF) & Italy & 1976 \\
\hline 3 & Hollister & USA & 1961 & 4 & Imperial Valley (NF) & USA & 1979 \\
\hline 5 & Kobe (NF) & Japan & 1995 & 6 & Kocaeli (NF) & Turkey & 1999 \\
\hline 7 & Landers & USA & 1992 & 8 & Loma Prieta & USA & 1989 \\
\hline 9 & Northridge (NF) & USA & 1994 & 10 & Trinidad (NF) & USA & 1983 \\
\hline 11 & Mexico City & Mexico & 1985 & 12 & Pulse & Synthetic & \\
\hline
\end{tabular}
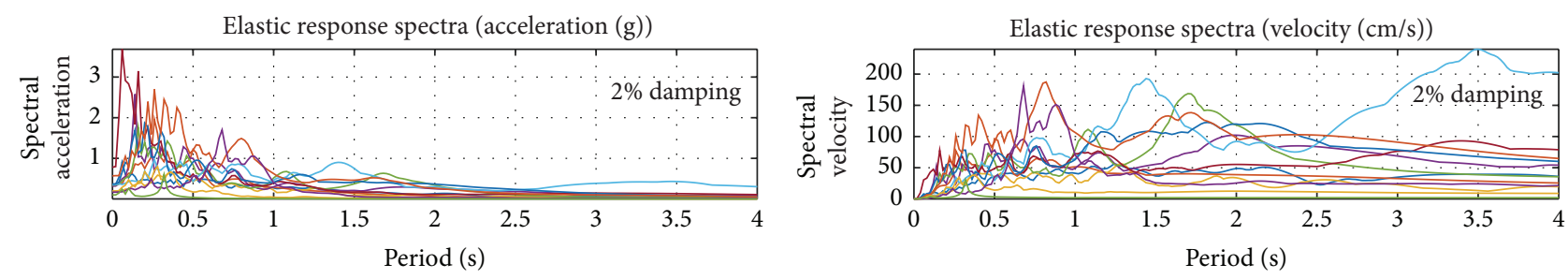

$\begin{array}{ll}- \text { (1) Chi-Chi } & - \text { (7) Landers } \\ \text { (2) Friuli } & - \text { (8) Loma Prieta } \\ \text { (3) Hollister } & - \text { (9) Northridge } \\ \text { (4) Imperial Valley } & - \text { (10) Trinidad } \\ \text { (5) Kobe } & - \text { (11) Mexico } \\ \text { (6) Kocaeli } & - \text { (12) Pulse }\end{array}$

(a)

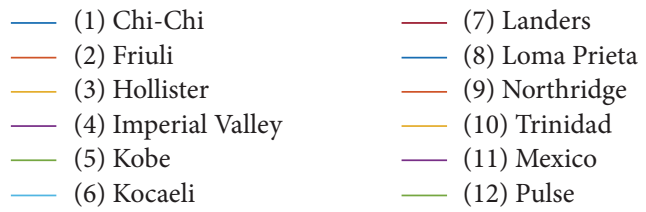

(b)

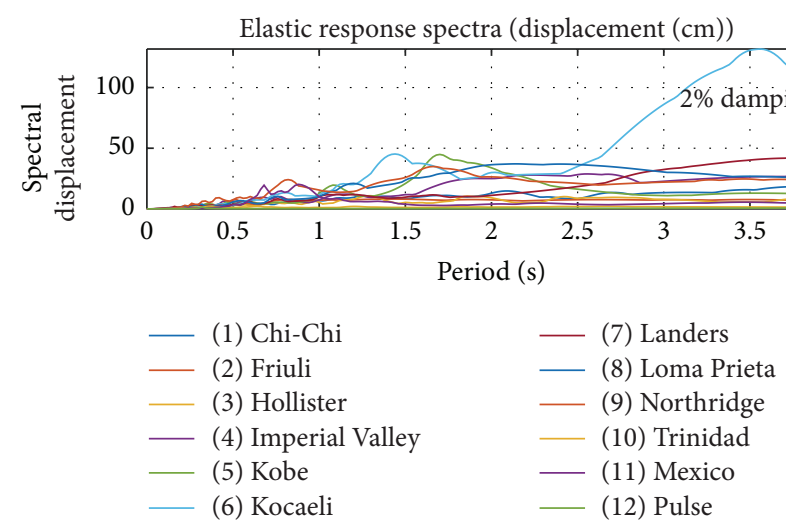

(c)

FIGURE 2: Elastic response spectra of the utilized ground motions: (a) acceleration; (b) velocity; (c) displacement.

vibration period of around $1.40 \mathrm{sec}$, which is the Kocaeli earthquake, Turkey, 1999. The elastic acceleration, velocity, and displacement response spectra of the earthquakes are shown in Figure 2 at a $2 \%$ damping. The low value of damping ratio was selected based on a recent study [33], which revealed (based on nonlinear time-history analysis results) that the damping ratio as well as the approach used to model damping has significant effects on the response, and, quite importantly, a damping ratio of around $1 \%$ is more appropriate in simulating the response than a damping ratio of $5 \%$. The present paper is based on nonlinear time-history analysis too. Therefore, a compromise between the commonly selected damping value (of $5 \%$ ) and the suggested one (of $1 \%$ ) is chosen as $2 \%$ herein.
Numerous parameters of a ground motion have been proposed over the years to characterize ground motions and to serve as indices of their damage potential. Such indices are often called "intensity measures." Such intensity measures include the Arias intensity, the Housner intensity, the RMS acceleration or velocity or displacement, the characteristic intensity, the specific energy density, the cumulative absolute velocity, the sustained maximum acceleration and velocity, acceleration and velocity spectrum intensity, the acceleration parameter A95, and the predominant period. Plots of eighteen of those intensity measures are shown in Figures 3 and 4 for all the selected ground motions. According to Figures 2, 3, and 4, the considered earthquakes are categorized into high-frequency earthquakes (HFE), 


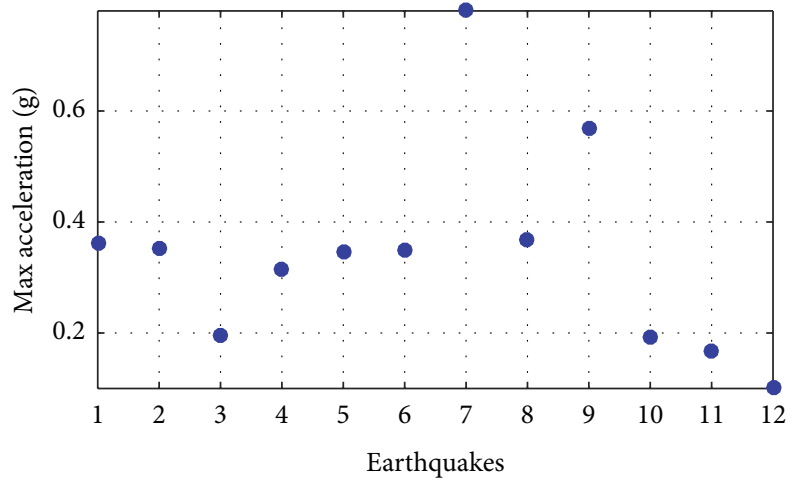

(a)

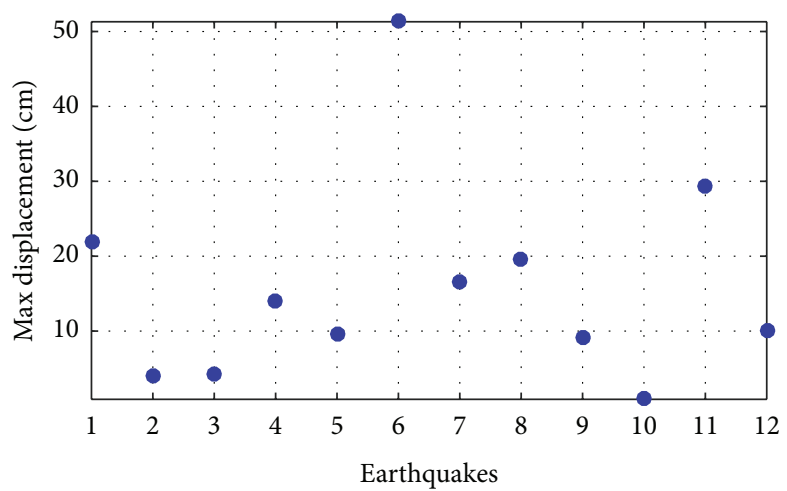

(c)

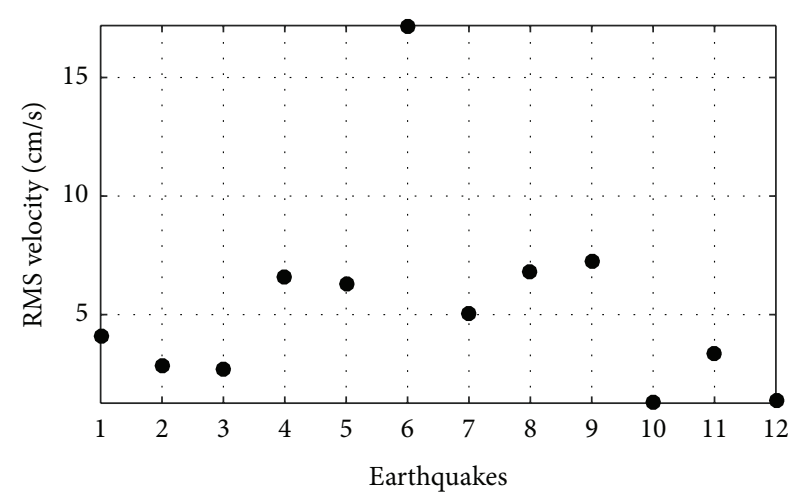

(e)

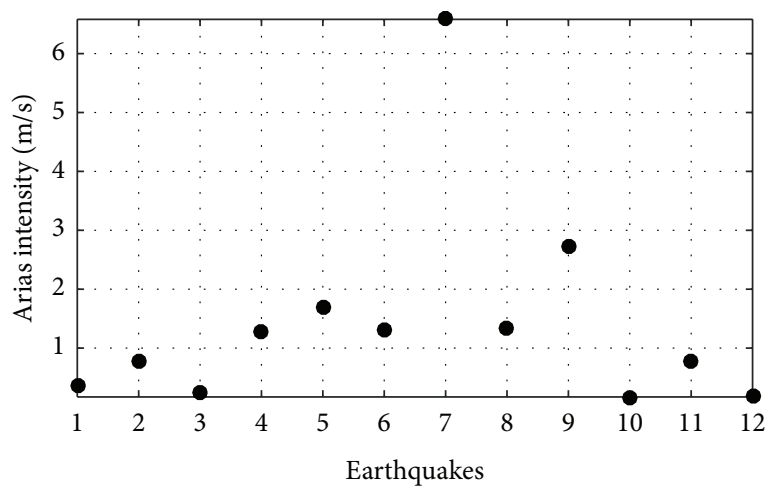

(g)

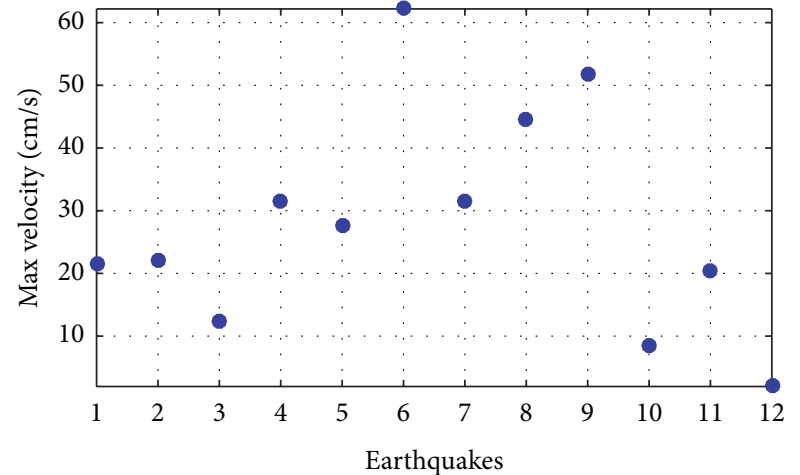

(b)

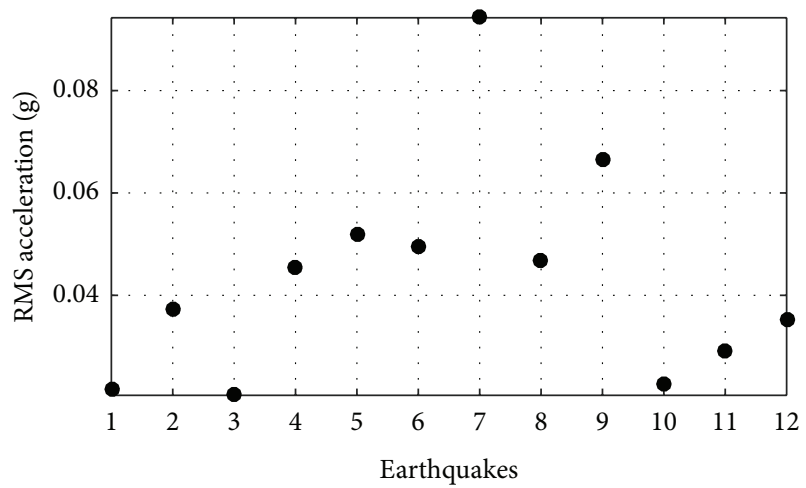

(d)

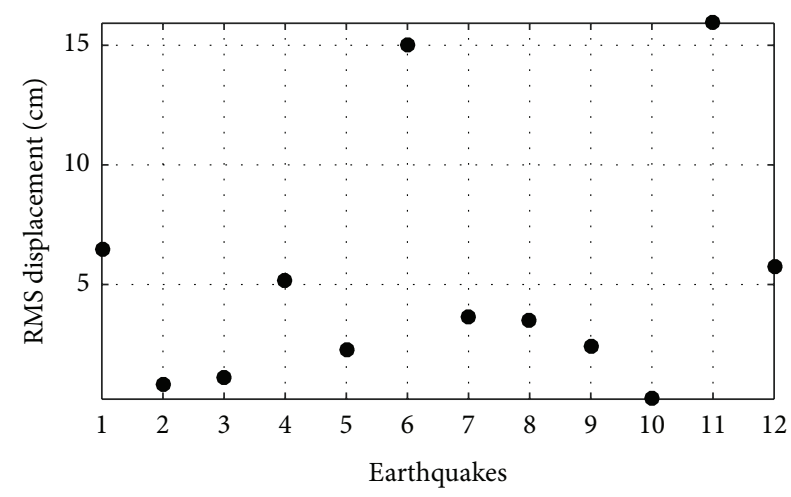

(f)

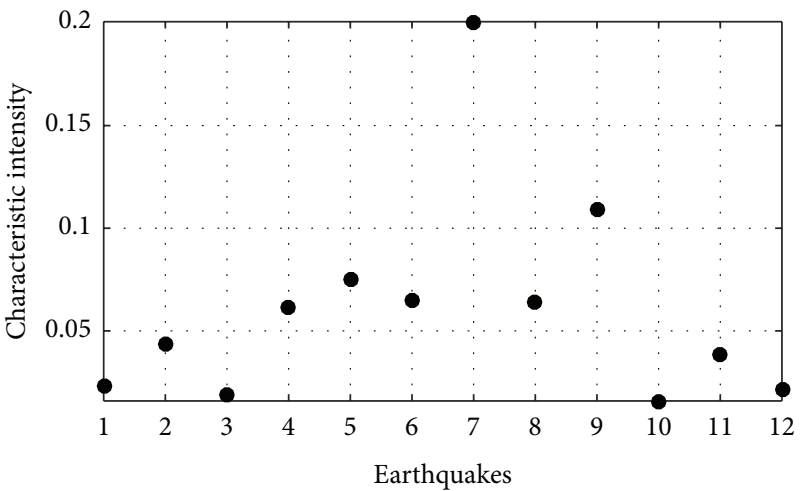

(h)

FIgure 3: Continued. 


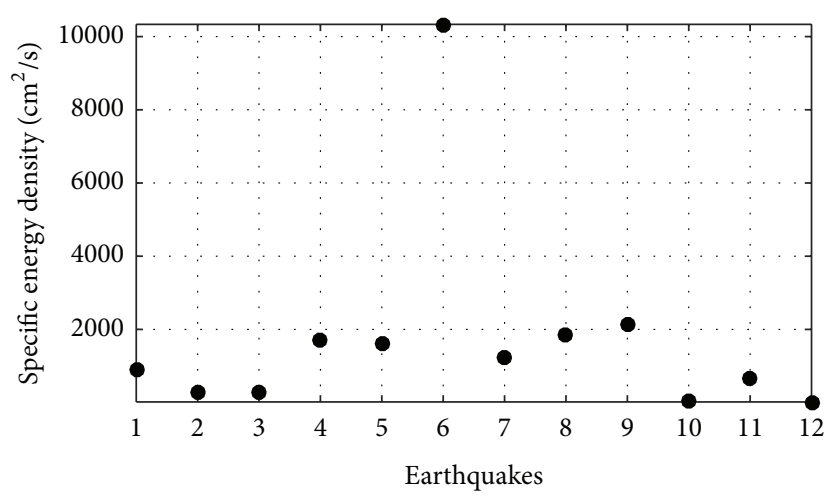

(i)

FIGURE 3: Characteristics of the utilized ground motions.

long-period earthquakes (LPE), and pulse-like earthquakes (PLE), which are associated with near-fault records.

\section{Isolated Bridge}

3.1. Bridge Model. A prestressed concrete box-girder bridge is used in this study. The bridge's length is divided into three spans longitudinally: two edge spans of $20.0 \mathrm{~m}$ and an intermediate one of $30.0 \mathrm{~m}$. The cross-sectional configurations and dimensions of the bridge deck are shown in Figure 5. The section's total width is $11.0 \mathrm{~m}$ including three vents, four girders, and double side-cantilevers of $0.90 \mathrm{~m}$ length each. The section's dimensions and depth are constant over the entire bridge's length. The bridge is supported on two intermediate piers and two edge abutments. The piers are T-shaped and identical with column/cantilever cross-sectional dimensions of $1.20 \mathrm{~m}$ width by $1.60 \mathrm{~m}$ depth, with a total height of $8.0 \mathrm{~m}$ from the pile cap's top surface. The piers are assumed to be completely fixed to their pile caps. The bridge superstructure's self-weight is $14250 \mathrm{kN}$ including the two intermediate piers (each weighs $732 \mathrm{kN}$ ). The bridge was designed based on the AASHTO [34]. The bridge is analyzed and investigated using Finite Element- (FE-) based nonlinear time-history analysis. The structural components of the bridge's deck box section are modeled using solid FE elements, while piers are modeled using FE beam elements.

Four FE identical models of the bridge are shown in Figure 6, and each is seismically isolated using one type of the four isolation systems considered herein, which are the RNC, friction pendulum systems (FPS), high damping rubber (HDR), and lead rubber bearing (LRB) isolation systems. The isolation bearings are located just below the bridge deck and above the supporting structures (piers and abutments). Each of the five bridge FE models (the above four and the fixedbase one) is modeled, analyzed, and investigated separately. The fixed-base case refers to the bridge's deck when it is fixed against horizontal translation to the supporting structure of piers and abutments. On the other hand, isolated case refers to the lateral separation of the bridge's deck from the supporting structures by means of isolation bearings. Each of the twelve ground motions is applied twice (not simultaneously): once longitudinally and the other time transversally. The influence of soil-foundation interaction is not considered in this study.

Due to the model complexity, high number of vibration modes (beyond 70 modes) were considered to achieve a dynamic modal load participation ratio close to $99 \%$. The first three vibration modes of the nonisolated bridge are longitudinally translational (modal period is $0.794 \mathrm{sec}$ ), torsional about the bridge's vertical axis (modal period is $0.655 \mathrm{sec}$ ), and transversally translational (modal period is $0.647 \mathrm{sec}$ ).

3.2. The RNC Isolator. Due to the design limitations and functional drawbacks of the existing isolation systems, in Section 1, the RNC isolator has been proposed, [22] as an attempt of enhancement; see Figure 7. It is a rolling-based isolation system to achieve the maximum possible structureground decoupling, which minimizes the seismic force transfer to the isolated structure. It is designed to achieve a balance in controlling isolator's peak displacement demands and peak absolute structural accelerations of isolated structure. It provides in a single unit all the necessary functions of vertical rigid support, horizontal flexibility with enhanced stability, hysteretic energy dissipation, and resistance to minor vibration loads. Although the rolling core is quasiellipsoidal, the RNC isolator generates no vertical fluctuation of isolated structure during motion due to the inner curvatures of the upper and lower bearing plates. Moreover, the RNC isolator is distinguished by four unique features: (1) a self-stopping (buffer) mechanism to limit the isolator displacement under severe abrupt seismic excitations, such as near-fault earthquakes, to a preselected value by the structural designer; (2) a linear gravity-based self-recentering mechanism that prevents residual permanent displacements after earthquakes (such recentering mechanism is a result of adopting a quasiellipsoidal shape of the rolling core); (3) a notable resistance to axial tension to resist overturning failure of isolated structure; and (4) the ability to provide hysteretic damping in the vertical direction, which would enable vertical shock absorbing capability, simultaneously with multi/unidirectional horizontal isolation. 


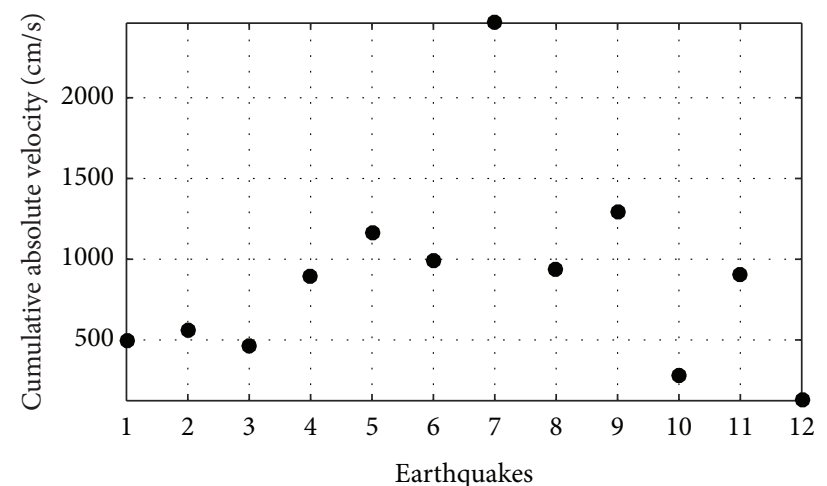

(a)

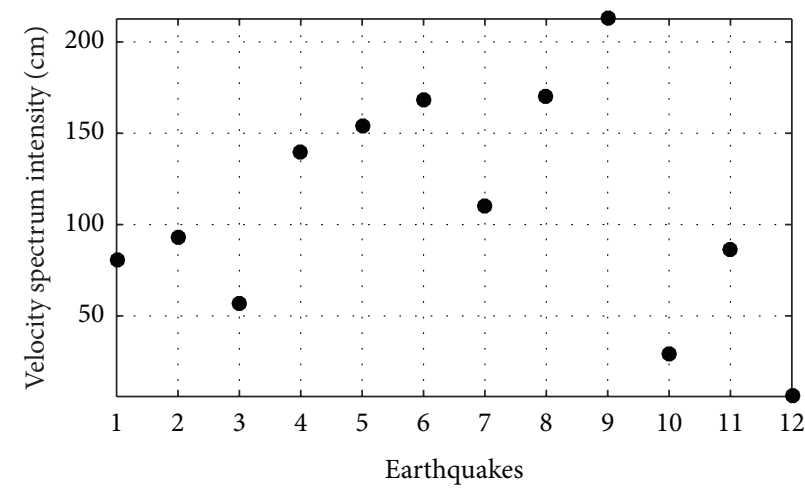

(c)

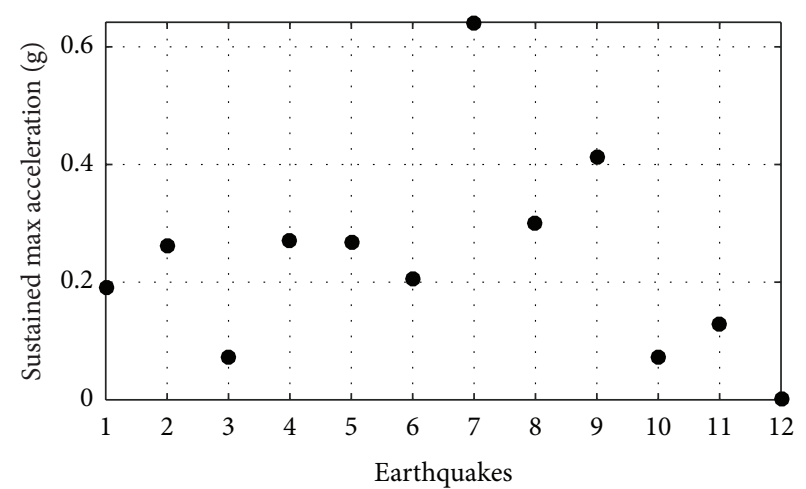

(e)

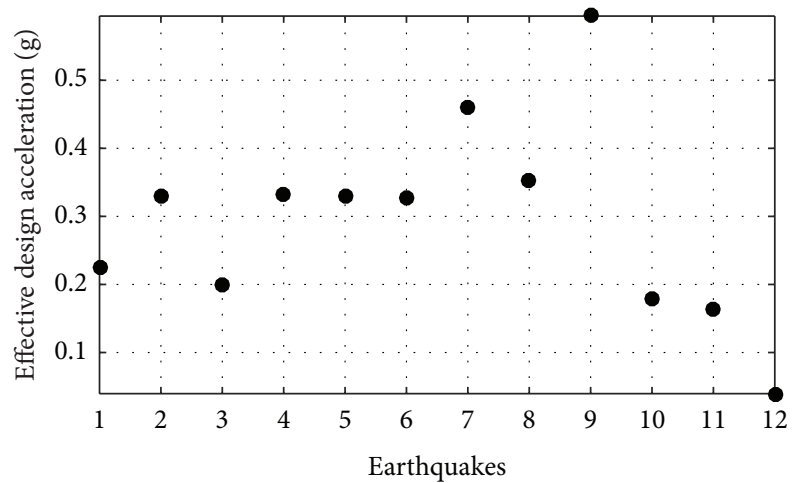

(g)

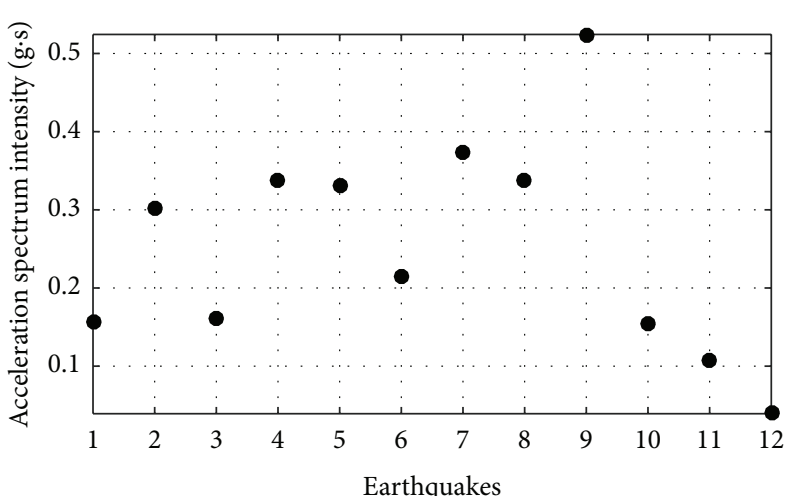

(b)

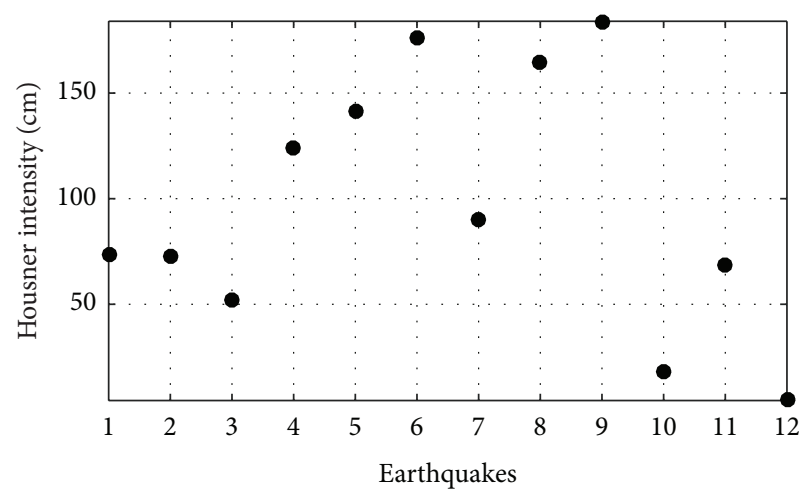

(d)

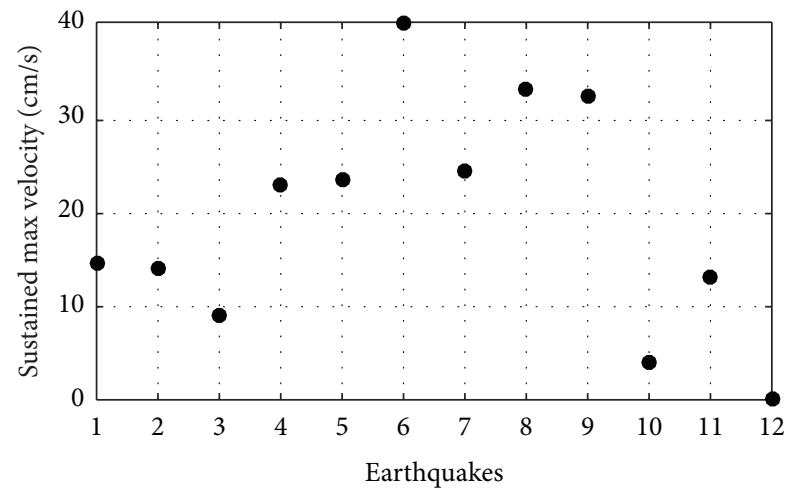

(f)

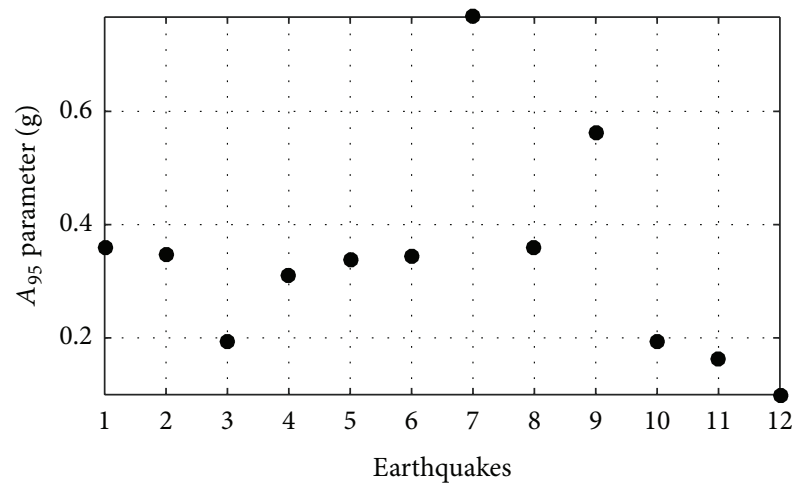

(h)

FIGURE 4: Continued. 


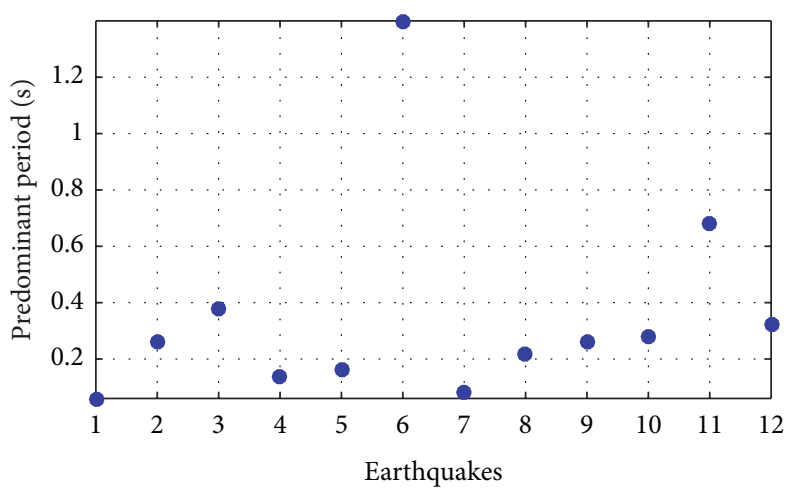

(i)

FIGURE 4: Additional characteristics of the utilized ground motions.

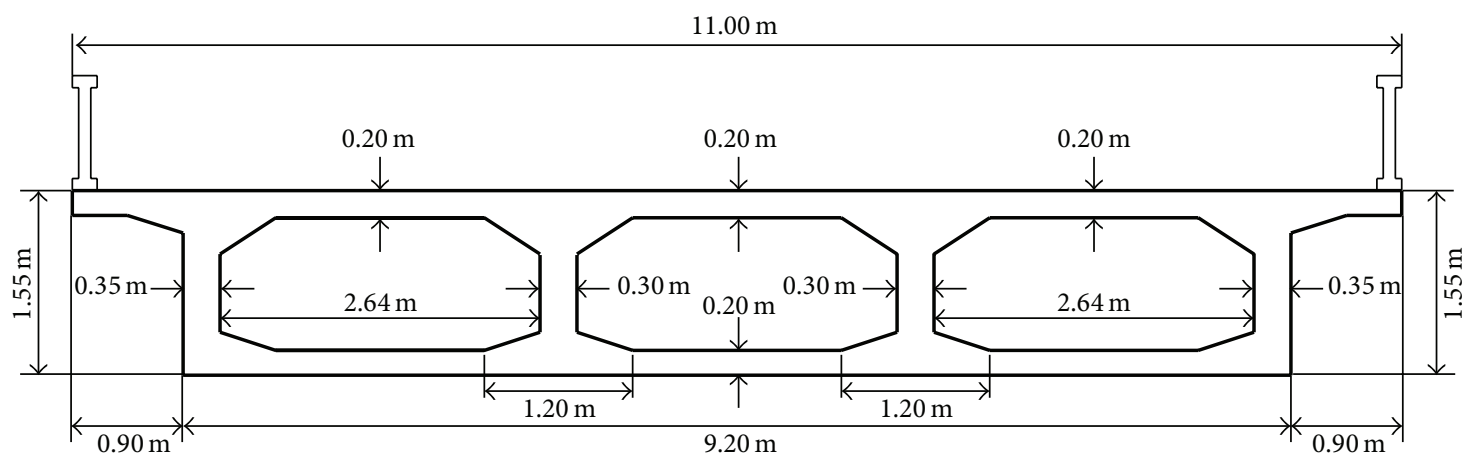

Figure 5: Cross-sectional configurations and dimensions of the considered bridge.

Besides the rolling-based motion mechanism, which requires less lateral forces to initiate and maintain high degree of structure-ground decoupling compared to other motion mechanisms of the elastomeric-based and frictionbased isolation systems, the RNC isolator is provided with a consistent design of the lateral stiffness/damping mechanism to get the most benefits of that rolling-based motion mechanism. Such design advantage lies in the independency of both vertical bearing mechanism and the mechanism that provides lateral preyield stiffness against minor vibration loads. This independency allows for accurate tuning (or high sensitivity) of the initial preyield stiffness to permit the commencement of the seismic isolation process, or structureground decoupling, just after the seismic forces exceed a maximum limit of minor vibration loads, contrary to the available isolation systems. To support heavy and extra heavy structures, the RNC isolator is provided with a linear hollow elastomeric cylinder, with a designed thickness, around the rolling core to represent the main vertical load carrying capacity, while the rolling core itself works as a secondary support in this case; see Figure 7. The RNC isolator can be available in different other forms to suit the structure or object to be protected. More detailed description and thorough treatment of the RNC isolator is found in Ismail [22].

As for the construction material of the RNC isolator, it is based on the component. Principally, the RNC isolator consists of 5 main components: upper bearing plate (UBL); lower bearing plate (LBP); quasiellipsoidal rolling core (RC); metallic yield dampers (MYD); and two rubber plates or rings (RPL). The UBP, LBP, and RC are made always of a stiff metal or alloy such as carbon steel. The MYD are made from a material with dominant plastic behavior under large displacements such as mild steel or copper. The RPL are made of durable rubber compound. Regarding dimensions of a RNC isolator in general, it is mainly based on the needed lateral peak displacement limit (PDL), after which the inherent self-stopping mechanism is self-activated. For example, to provide a lateral displacement PDL of $600 \mathrm{~mm}$, the RNC isolator height would be around $1000 \mathrm{~mm}$ and the in-plan diameter would be around $1500 \mathrm{~mm}$ at the neutral undeformed position. Those dimensions are chosen at present by trial and error method until developing a systematic design approach for the RNC isolator in the near future.

3.3. The RNC Isolator's Working Principles. Before an earthquake (ground motion), the RNC isolator takes the shape shown in Figure 7, referred to as neutral (undeformed) position. During an earthquake, a sudden horizontal ground motion moves laterally the lower bearing plate (LBP) relative to the upper bearing plate (UBP). The UBP (supporting isolated structure/object) is intended to exhibit 


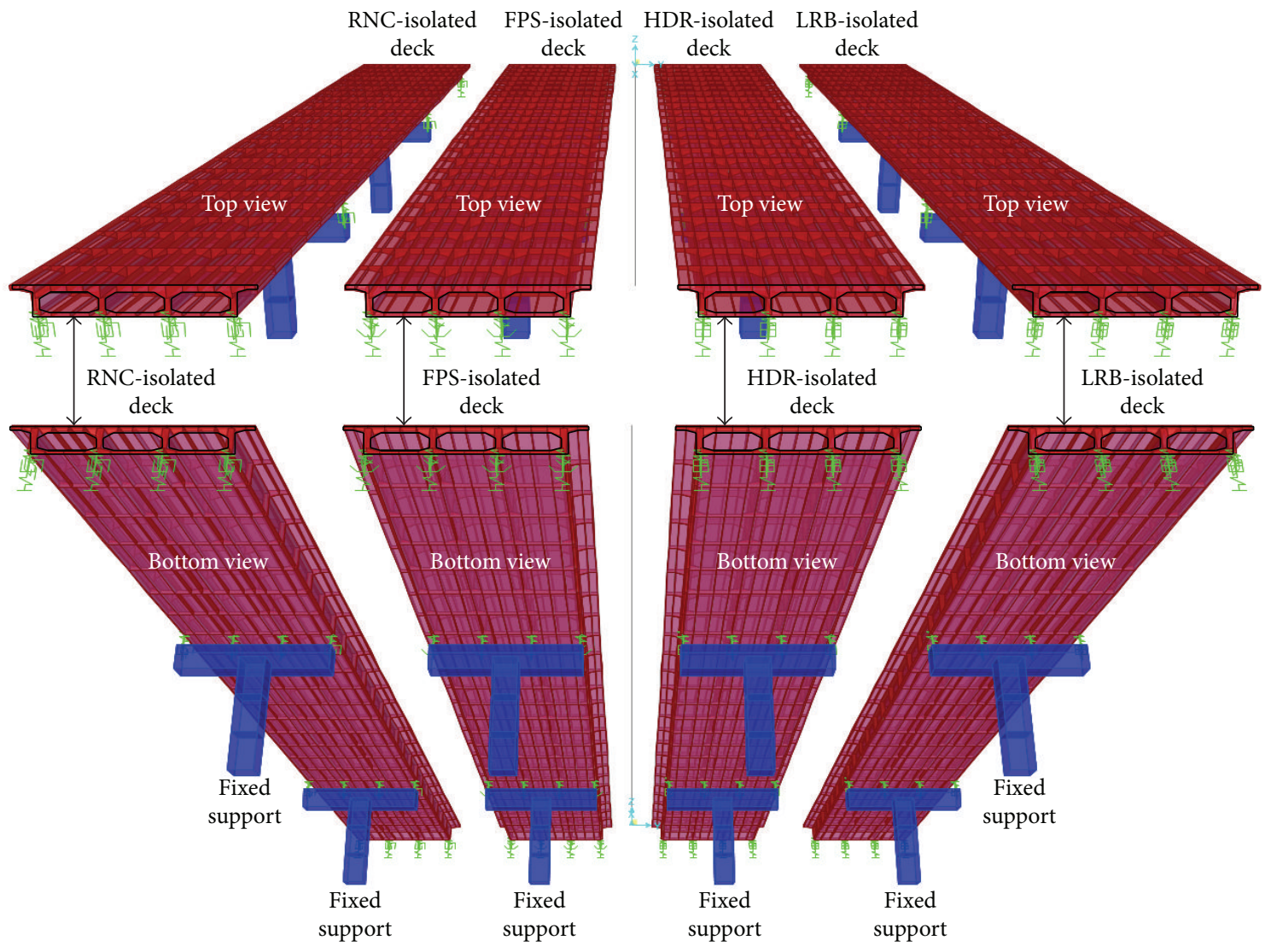

FIGURE 6: FE model of isolated identical bridges using RNC, FPS, HDR, and LRB isolation systems.

minimum or zero motion during an earthquake due to prompt smooth/frictionless lateral rolling of a nondeformable quasiellipsoidal rolling core (RC), accompanied by low lateral stiffness of metallic yield "dampers." A relative lateral displacement between LBP and UBP stretches the curved dampers and generates hysteretic energy dissipation along the direction of motion. Rolling of the RC dissipates ground motion, while hysteretic damping dampens any transmitted energy to the isolated structure and reduces its peak displacement amplitude. Each damper's shape includes triple curvatures to provide enough extension during the RC's lateral rolling and to minimize stress concentrations at the damper's bends to increase its working life.

Inner surfaces of bearing plates (facing the RC) are curved to completely absorb increasingly developed uplift (of UBP and isolated structure/object) due to rolling of the quasiellipsoidal (this shape provides inherent gravitybased recentering mechanism) RC. This no-uplift mechanism prevents generating vertical fluctuations out from purely horizontal vibrations.

The device is provided with an inherent peak displacement limit (PDL), after which the self-stopping (buffer) mechanism is self-activated to prevent excessive displacements beyond that limit. The PDL is chosen by the designer as needed based on the actual situation (structural and excitation's properties). The buffer may limit peak displacements via inner pounding, which is self-mitigated in two ways inside the RNC isolator: (1) elastomeric buffer's parts cover the metallic buffer's parts to avoid direct poundingcontact between two metallic components (the RC grooves and the corresponding buffer metallic stoppers); (2) extreme stretching of the curved dampers (at large horizontal relative displacements between $\mathrm{UBP}$ and LBP) reduces the RC's rolling velocity before hitting the buffer and therefore decreases its kinetic energy to result in lower inner pounding that could be absorbed by the buffer's elastomeric parts. After the earthquake, the inherent self-recentering returns the device to its original neutral position (shown in Figure 7) with zero permanent/residual displacements, and the dampers restore their initial shapes.

3.4. Other Isolation Systems Used Herein. In addition to comparing the RNC-isolated bridge's responses to their corresponding ones on the nonisolated case, a set of three other isolation systems are used for comparing their behaviors to that of the RNC isolator. Those three isolation systems, which are widely used at present, are LRB, HDR, and FPS mentioned in Section 1. The same bridge structure is isolated four times, each using only a single type among the four used bearing types under exactly the same loading conditions; see Figure 6. 


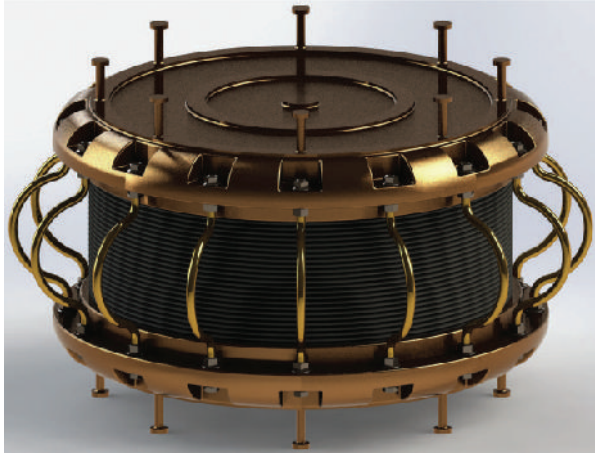

(a)

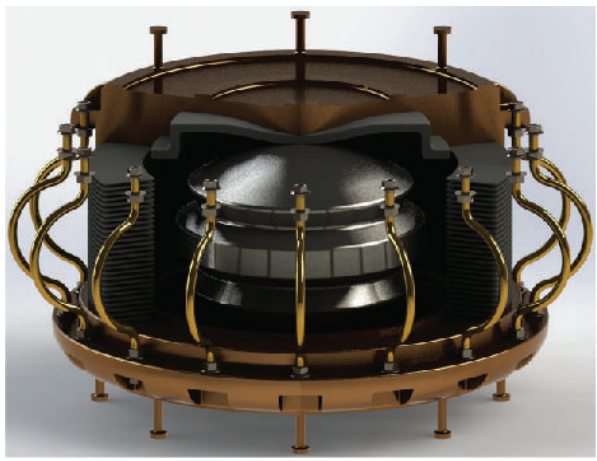

(c)

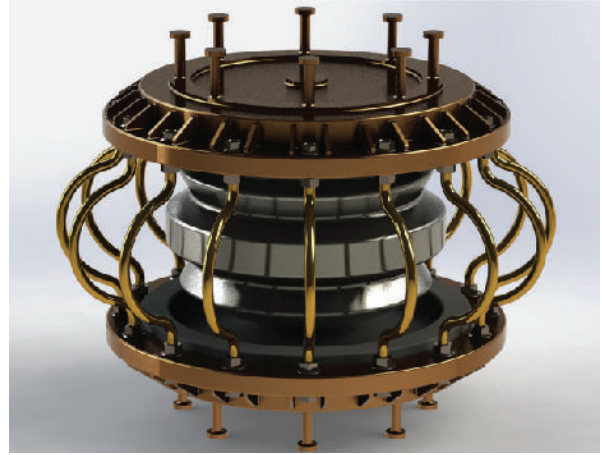

(b)

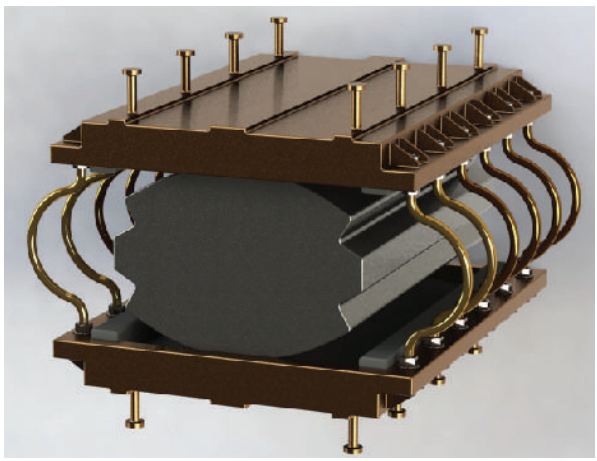

(d)

Figure 7: The RNC isolator designs for (a) a multidirectional/heavy-loads; (b) a multidirectional/light- to moderate-loads; (c) sectional view of the multidirectional/heavy-loads; (d) a unidirectional/light- to moderate-loads.

Table 2 shows a comparison between the used four isolation systems considering 24 design criteria needed for efficient seismic isolation.

The RNC isolator is designed at present using trial and error, while the other three isolation systems were designed based on AASHTO [34] and FEMA [35]. Initially, all isolation systems were designed to provide a fundamental vibration period of $2.50 \mathrm{sec}$ after isolation (nearly three times that of the fixed-base case). Then, all the bearings designs were tuned (or optimized) using a trial and error method to provide the best behavior possible (in terms of low structural accelerations and accompanying peak bearing displacements). At the beginning, the bearings were designed to provide a peak horizontal displacement of $300 \mathrm{~mm}$. Then, their designs were updated as needed based on successive runs to accommodate their actual peak displacements after those runs.

3.5. Modeling of the Used Isolation Systems. The elastomeric LRB and HDR are modeled as biaxial hysteretic isolators that have coupled plasticity properties for the two shear deformations and linear effective-stiffness properties for the remaining four deformations. The plasticity model is based on the hysteretic behavior proposed by Nagarajaiah et al. [36], Park et al. [37], and Wen [38].

The FPS is modeled as a biaxial friction pendulum isolator that has coupled friction properties for the two shear deformations, postslip stiffness in the shear directions due the pendulum radii of the slipping surfaces, gap behavior in the axial direction, and linear effective-stiffness properties for the three moment deformations. The friction forces and pendulum forces are directly proportional to the compressive axial force in the element. The element can not carry axial tension. The model does not take into account temperatureand velocity-dependent variation of the coefficient of friction. The friction model is based on the hysteretic behavior proposed by Nagarajaiah et al. [36], Park et al. [37], and Wen [38]. The pendulum behavior is based on Zayas et al. [39].

The RNC isolator's features are modeled based on the derived multifeature $3 \mathrm{D}$ modeling by Ismail [40, 41], which takes into account the main and unique features of the RNC isolator. Those modeled features include vertical rigidity, multidirectional horizontal flexibility and hysteretic damping, gravity-based self-recentering, self-stopping, a peak lateral displacement limit, no vertical fluctuation due to purely horizontal motion, and pre- and postyield stiffness.

\section{Comparative Study}

A large amount of outputs were obtained based on the comparative study performed. Therefore, and due to space limitations, certain sets of outputs are presented in this section and divided into three main subsections including the influence of isolation on the bridge's internal forces (Section 4.1), on the deck's accelerations and displacements (Section 4.2), and on the input seismic energies to the bridge (Section 4.3). 
TABLE 2: A comparison between the used four isolation systems.

\begin{tabular}{|c|c|c|c|c|}
\hline Design feature, functionality, or behavior criterion & HDR & LRB & FPS & RNC isolator \\
\hline (1) Lateral energy dissipation mechanism & $\checkmark$ & $\checkmark$ & $\checkmark$ & $\checkmark$ \\
\hline (2) Vertical energy dissipation mechanism & & & & $\checkmark$ \\
\hline (3) Self-stopping or buffer mechanism & & & & $\checkmark$ \\
\hline (4) No $P$-delta effect & & & $\checkmark$ & $\checkmark$ \\
\hline (5) No risk of buckling failure & & & $\checkmark$ & $\checkmark$ \\
\hline (6) Stiffness- and mass-dependent vibration period & $\checkmark$ & $\checkmark$ & & $\checkmark$ \\
\hline (7) Low accelerations of isolated systems & & & & $\checkmark$ \\
\hline (8) Reduced torsional responses of isolated systems & & & $\checkmark$ & $\checkmark$ \\
\hline (9) No minimum flexibility limit & & & $\checkmark$ & $\checkmark$ \\
\hline (10) Nonchanging friction coefficient with velocity & $\checkmark$ & $\checkmark$ & & $\checkmark$ \\
\hline (11) High resistance to vertical axial tension & & & & $\checkmark$ \\
\hline (12) Suitable for low-mass systems & & & $\checkmark$ & $\checkmark$ \\
\hline (13) Suitable for moderate- and heavy-mass systems & $\checkmark$ & $\checkmark$ & $\checkmark$ & $\checkmark$ \\
\hline (14) Self-recentering mechanism & & & $\checkmark$ & $\checkmark$ \\
\hline (15) Wide working ranges of stiffness and damping & & $\checkmark$ & $\checkmark$ & $\checkmark$ \\
\hline (16) Resistance to wind loads and minor vibrations & $\checkmark$ & $\checkmark$ & $\checkmark$ & $\checkmark$ \\
\hline (17) Strain-independent stiffness and damping & & $\checkmark$ & $\checkmark$ & $\checkmark$ \\
\hline (18) Independent lateral stiffness and vertical bearing mechanisms & & & & $\checkmark$ \\
\hline (19) Independent damping and vertical bearing mechanisms & & & & $\checkmark$ \\
\hline (20) Independent tension-resistance and vertical bearing mechanisms & & & & $\checkmark$ \\
\hline (21) Vertical bearing capacity not affected by shear strain & & & $\checkmark$ & $\checkmark$ \\
\hline (22) Flexible replacement and selection of dampers material and dimensions & & & & $\checkmark$ \\
\hline (23) Low initial lateral stiffness & $\checkmark$ & $\checkmark$ & & $\checkmark$ \\
\hline (24) Horizontal fail-safe mechanism & & & & $\checkmark$ \\
\hline Criteria fulfilment ratio & $6 / 24$ & $8 / 24$ & $12 / 24$ & $24 / 24$ \\
\hline Criteria fulfilment percentage & $25 \%$ & $33 \%$ & $50 \%$ & $100 \%$ \\
\hline
\end{tabular}

\subsection{Influence of Isolation on the Bridge's Internal Forces}

4.1.1. Pier's Cantilever. This section addresses the RNC isolator's behavior (relative to other isolations systems) in reducing the bridge's internal forces, particularly into the supporting structure of the bridge. This is intended to highlight the (relative) potential efficiency of the RNC isolator in reducing those forces. Each variable (or internal force) is selected to reflect a certain degree of transmissibility of seismic forces into the bridge structure. A schematic plot of the main considered pier sections and their internal forces is demonstrated by Figure 8. For example, Figure 9(a) displays a bar chart of peak torsional moments developed into the pier's cantilever under twelve excitations, considering five cases: fixed-base and isolated using LRB, HDR, FPS, and RNC isolation systems. The selection of this variable (cantilever torsion) could be used as a measure of the transmitted horizontal shear forces (at the bearing level) in the bridge's longitudinal direction. Such shear forces are eccentric from the cantilever's longitudinal axis leading to cantilever torsion. Since the eccentricity (vertical distance between the bearing's lower face and the cantilever's longitudinal axis) is fixed, the value of transmitted horizontal shear forces (from the deck to the pier) in the bridge's longitudinal direction could represent a practical measure of isolation efficiency along that direction.

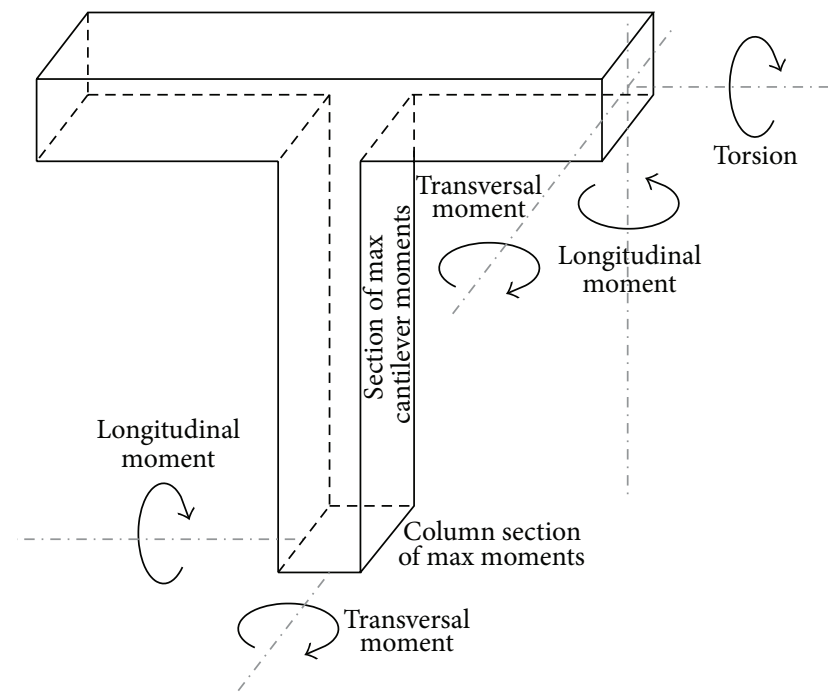

FIGURE 8: Schematic plot of the considered pier sections and internal forces.

Based on Figure 9(a), the highest peak torsion is produced by Northridge and Imperial Valley earthquakes, which are near-fault pulse-like earthquakes, besides the Kocaeli 


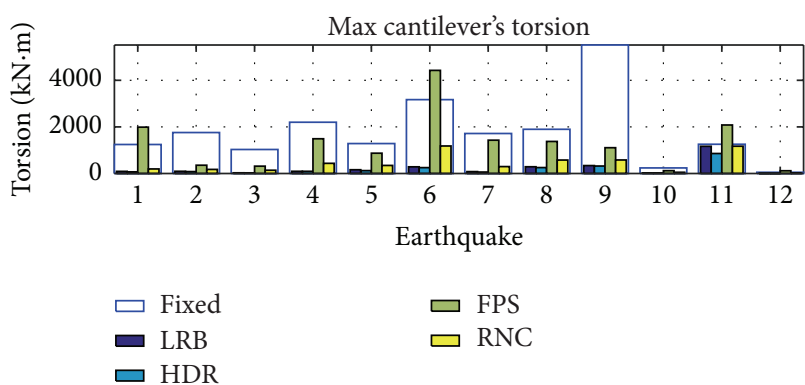

(a)

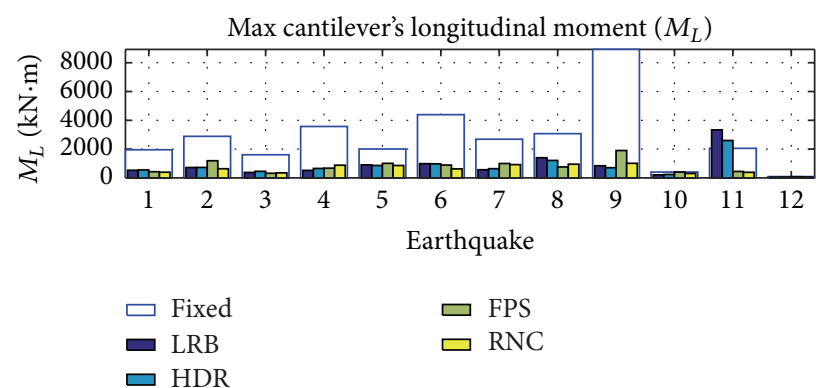

(b)

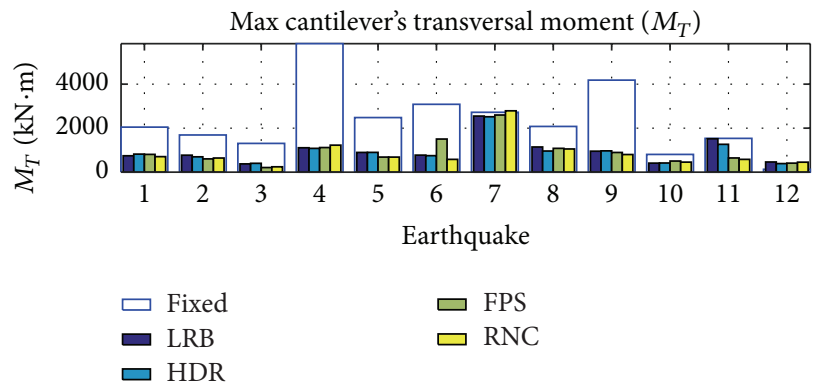

(c)

FiguRE 9: The pier's cantilever peak moments: (a) torsion; (b) longitudinal moment; (c) transversal moment.

earthquake, which is a near-fault long-period earthquake. Regarding the isolation effects, the general trend is that isolation reduces reasonably the cantilever's torsion. However, this effect is relatively different and is dependent on the isolation system used. A common observation is the relative efficiency of the HDR and the relative deficiency of the FPS, which magnified the peak responses beyond the original fixed-base ones, especially under Chi-Chi, Kocaeli, Mexico City, and the synthetic pulse earthquakes. Those four ground motions comprise high vibration frequencies, long dominant periods, and high velocity and displacement pulses. This indicates an independent (relatively inefficient) behavior of the FPS to the ground motion characteristics regarding the cantilever torsion. Another observation is the relatively neutral (close to fixed-base case) behaviors of the LRB, HDR, and RNC isolator under the long-period Mexico City earthquake relative to other earthquakes, especially the Kocaeli earthquake having longer dominant period. This may reveal the negative influence of certain long-period earthquakes on the isolation behavior, mainly the FPS system in this study that proved inefficient under this type of ground motions considering cantilever's torsion. It is worth noting that the relatively high cantilever torsion using the FPS is translated into additional longitudinal reinforcement for the cantilever, in addition to the pier's column in order to balance that torsion, which means added construction costs.

To highlight the relative efficiency of all the four isolation systems, a relative efficiency or ranking measure is proposed based on the ratio of two numbers: the number of (isolation) load cases per figure in which the isolator was found the most relatively efficient in reducing the peak isolated responses relative to their corresponding fixed-base ones and the number of (isolation) load cases per figure in which the isolator was the least relatively efficient one. The higher the ratio, the higher the isolator efficiency, and consequently the higher its rank relative to others. However, in case the denominator would be zero, it is taken as one to avoid division by zero. Table 3 lists those ratios and the resulting relative ranking of the four isolation systems based on the studies performed in Section 4.1. According to Figure 9(a) and Table 3 (Line 1), the first (relatively best) and last (relatively worst) ranks are of HDR and FPS, respectively. The LRB and RNC isolator come in the second and third ranks, respectively, but without exceeding any of the fixed-base responses.

Similarly, the variable of max cantilever's moment $\left(M_{L}\right)$, due to the same above shear component along the bridges' longitudinal direction, is considered in Figure 9(b). This moment is measured at the pier's column lateral face and represents another measure of such transmitted shear components considered in Figure 9(a). Except the inefficiency of both LRB and HDR under the long-period Mexico City earthquakes, isolation seems able to reduce $M_{L}$ under the remaining considered earthquakes. The high efficiency of the RNC isolator relative to other isolation systems is highlighted by Table 3 (Line 2), where the RNC isolator achieved the best relative behavior among the rest of systems followed by the LRB and HDR and finally comes the FPS as the least relatively efficient regarding the measured variable of $M_{L}$ in Figure 9(b).

The horizontal shear forces transmitted from the deck to the piers are measured in terms of the cantilever's bending moment about its horizontal axis. This moment is referred to as transversal moment $\left(M_{T}\right)$ as it is developed by ground motions in the bridge's transversal direction. Figure 9(c) 
TABLE 3: Relative efficiency measure of the four isolation systems based on their influence on the bridge's internal forces.

\begin{tabular}{|c|c|c|c|c|c|c|c|c|c|}
\hline & \multirow{2}{*}{ Figure number } & \multirow{2}{*}{ Figure description } & \multirow{2}{*}{ Number of load cases/figure } & \multicolumn{4}{|c|}{ Isolation system $\left(\right.$ ratio $\left.^{1}\right)$} & \multirow{2}{*}{ Least efficient ${ }^{2}$} & \multirow{2}{*}{ Most efficient ${ }^{3}$} \\
\hline & & & & LRB & HDR & FPS & RNC & & \\
\hline Line 1 & Figure 9(a) & Cant. torsion & 12 cases & $0 / 0$ & $12 / 0$ & $0 / 12$ & $0 / 0$ & FPS & HDR \\
\hline Line 2 & Figure $9(\mathrm{~b})$ & Cant. long. moment & 12 cases & $4 / 3$ & $1 / 2$ & $2 / 6$ & $5 / 1$ & FPS & RNC \\
\hline Line 3 & Figure $9(\mathrm{c})$ & Cant. trans. moment & 12 cases & $1 / 4$ & $4 / 4$ & $2 / 2$ & $5 / 2$ & $L R B$ & RNC \\
\hline Line 4 & Figure 10(a) & Pier long. moment & 12 cases & $4 / 4$ & $3 / 0$ & $1 / 5$ & $4 / 3$ & FPS & HDR \\
\hline Line 5 & Figure 10(b) & Pier trans. moment & 12 cases & $1 / 3$ & $2 / 4$ & $6 / 3$ & $3 / 2$ & $L R B$ & FPS \\
\hline Line 6 & Figure 11(a) & Base shear long. & 12 cases & $4 / 2$ & $2 / 0$ & $1 / 9$ & $5 / 1$ & FPS & RNC \\
\hline Line 7 & Figure 11(b) & Base shear trans. & 12 cases & $2 / 1$ & $3 / 2$ & $1 / 9$ & $6 / 0$ & FPS & RNC \\
\hline
\end{tabular}

${ }^{1}$ Ratio of two numbers: the number of load cases per figure in which the isolator was the most relatively efficient among the four types and the number of load cases per figure in which the isolator was the least relatively efficient one.

${ }^{2}$ The least relatively efficient isolation system (among the four types) in the study of the corresponding figure.

${ }^{3}$ The most relatively efficient isolation system (among the four types) in the study of the corresponding figure.

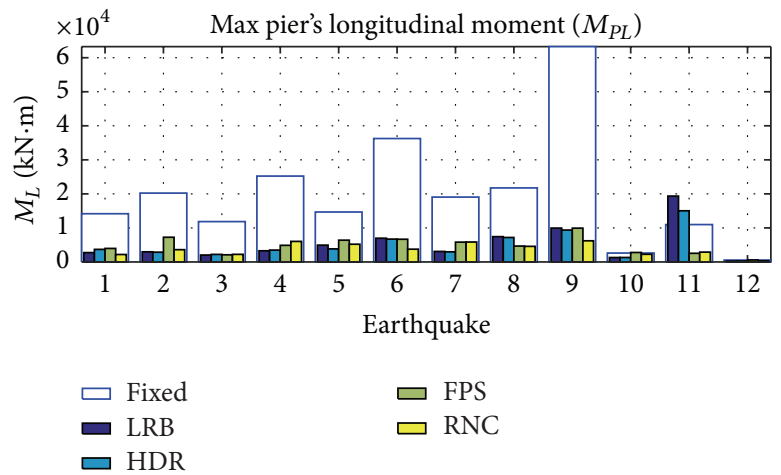

(a)

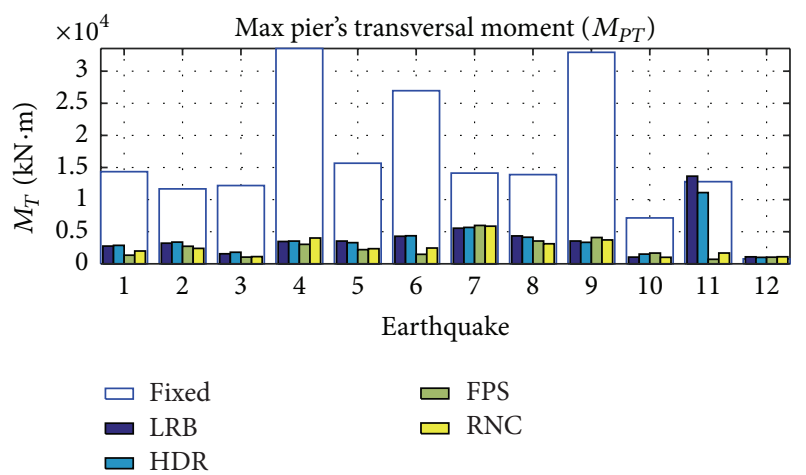

(b)

Figure 10: The pier's column peak moments: (a) longitudinal moment; (b) transversal moment.

shows the peak values of $M_{T}$ under the used excitations considering fixed-base and isolated cases. Seismic isolation seems able to reduce $M_{T}$, except being neutral under Landers earthquake and inefficient under the relatively weak synthetic pulse ground motion. Those two earthquakes have the highest and the lowest peak ground accelerations (PGA), respectively, as shown by Figure 3(a). However, the earlier earthquake has a mix of complex characteristics including high accelerations peaks and frequencies as well as displacement and velocity pulses as demonstrated by Figures 3 and 4 . Based on the relative efficiency measure in Table 3 (Line 3), which evaluates the bearings behaviors concerning the $M_{T}$ reduction, it is confirmed that the RNC isolator offers the relatively best dynamic behavior among all systems, while the LRB was found to be the least relatively efficient one.

4.1.2. Pier's Column. Two additional types of internal forces are of significant importance in structural engineering, which are the maximum bending moment at the pier's column base and the base shear of the entire bridge structure. The Pier's bending moment at the column base becomes more critical in cases of high piers and/or heavy decks, while the base shear reflects the total transmitted seismic forces into the entire structure. Figures 10(a) and 10(b) show the peak bending moments at the pier's column base due to the application of the twelve earthquakes longitudinally and transversally, respectively. In general, seismic isolation has notably reduced the peak values of those moments, except the relatively odd behaviors of LRB and HDR under the longperiod Mexico City earthquake. Such response reduction, by isolation, is highest under the near-fault Northridge and Imperial Valley earthquakes, which caused the worst fixed-base responses. Although the four isolation systems exhibit close performance under the same earthquake, some variations still exist to enable ranking those bearings from relatively best to relatively worst ones. Table 3 (Lines 4,5 ) reveals that the most relatively efficient isolators in reducing the peak longitudinal and transversal pier's moments are HDR and the FPS, respectively, while the least relatively efficient ones are the FPS (in longitudinal direction) and the LRB transversally. The RNC isolator is ranked the second best in both directions. The nearly similar results of the four isolators per earthquake (except earthquake number 11) ensure that, under the same earthquake, the pier's moment is independent of the isolators characteristics and each isolator behaves (nearly) independently of the ground motion characteristics.

4.1.3. Structural Base Shear. Figures 11(a) and 11(b) compare the peak structural base shear of the bridge under the 


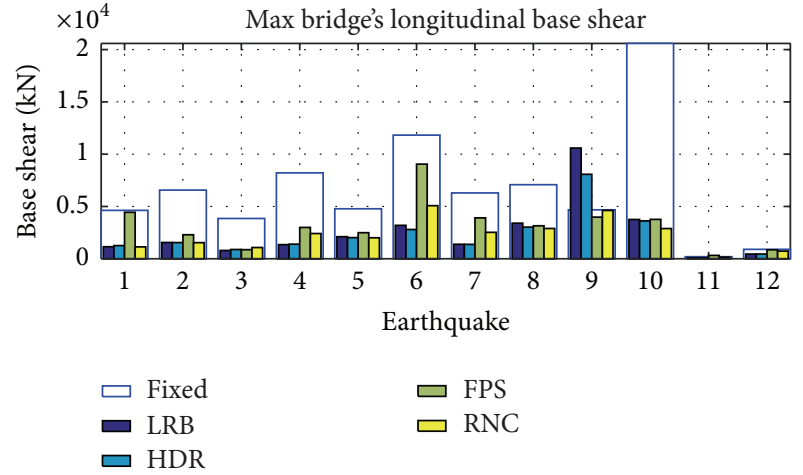

(a)

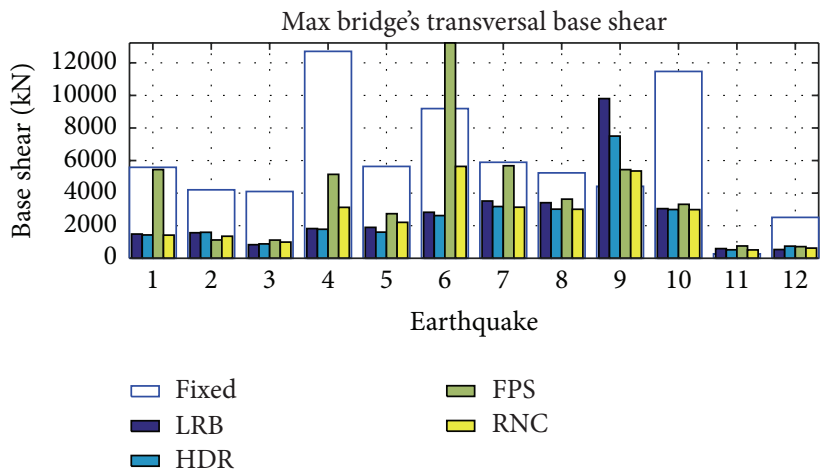

(b)

FIGURE 11: The bridge's base shear in (a) longitudinal direction; (b) transversal direction.

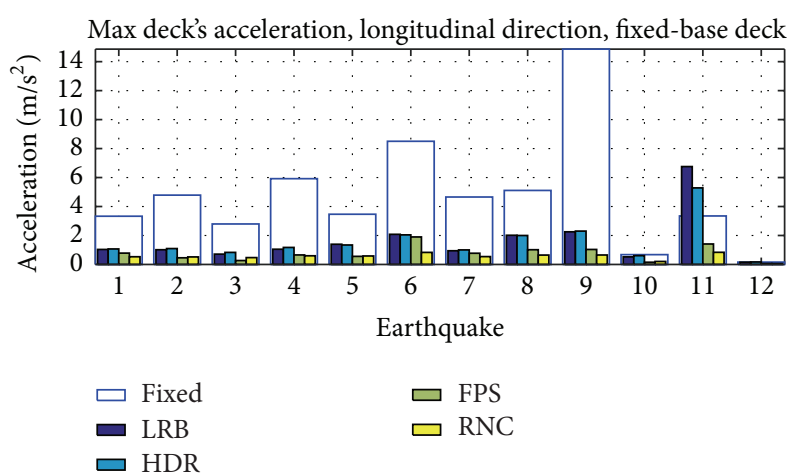

(a)

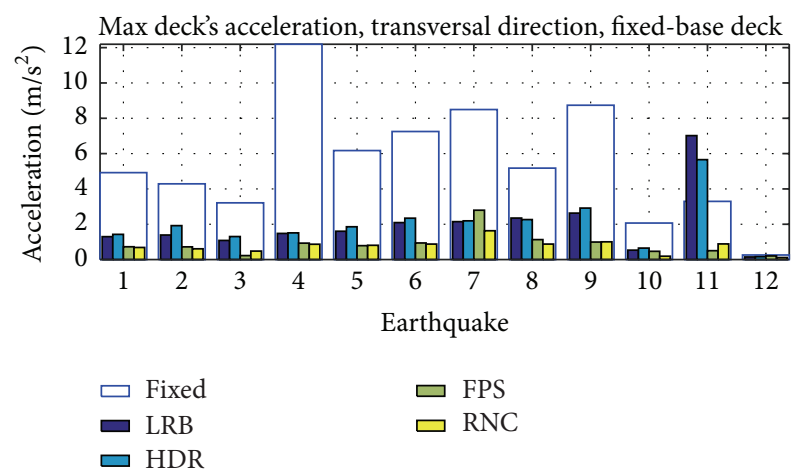

(b)

FIGURE 12: The deck's peak accelerations: (a) in longitudinal direction; (b) in transversal direction.

same ground motions considering fixed-base and isolated cases in longitudinal and transversal directions, respectively. Significant variations are obvious concerning the isolators performance in both directions. For example, all the four isolation systems are inefficient under the transversal Mexico City earthquake as they nearly doubled the structural base shear under that earthquake. In addition, both LRB and HDR are inefficient under longitudinal and transversal Northridge earthquakes. The FPS is also inefficient under the longitudinal Mexico City and the transversal Kocaeli earthquake, besides being neutral under Chi-Chi earthquake in both longitudinal and transversal directions as well as the longitudinal synthetic pulse ground motion. On the other hand, the RNC isolator is only inefficient under transversal Northridge earthquake and is neutral under its longitudinal component and likewise the longitudinal synthetic pulse earthquake. In the rest of cases, all the isolation bearings offer different degrees of response reductions. Accordingly, the isolation bearings have been significantly influenced by the variations in ground motion characteristics, especially those having long predominant periods and strong velocity/displacement pulses. To judge the bearings' relative behaviors, let us refer to Table 3 (Lines 6, 7). In both longitudinal and transversal directions, the RNC isolator has got the highest rank as being the most relatively efficient in reducing the bridge's base shear in those directions among other systems. On the other side, the FPS has got the lowest rank being the least relatively efficient bearing in the same study along both directions.

4.2. Influence of Isolation on the Deck's Accelerations and Displacements. Reducing the decks' peak absolute accelerations is a primary target of seismic isolation of bridges. In this section, those reduced peak accelerations are plotted in Figures 12(a) and 12(b) against their corresponding fixed-base ones in both longitudinal and transversal directions of the bridge, respectively. Except the inefficient performance of both LRB and HDR under the long-period Mexico City earthquake (longitudinally and transversally) and their neutral action under the longitudinal Trinidad earthquake, seismic isolation was found generally effective in mitigating peak deck's absolute accelerations. Based on the peak values of fixedbase accelerations, the longitudinal Northridge (number 9) and the transversal Imperial Valley (number 4) earthquakes are the most severe excitation in this study. However, the peak accelerations reduction is the maximum under those two earthquakes.

In general, it seems obvious that neither the excitations' characteristics nor the bearings' properties have negatively affected the remarkable mitigation of the deck's peak absolute accelerations (except the above inefficiency of LRB and HDR 
TABLE 4: Relative efficiency measure of the four isolation systems based on their influence on the deck's peak acceleration and displacement.

\begin{tabular}{|c|c|c|c|c|c|c|c|c|c|}
\hline & \multirow{2}{*}{ Figure number } & \multirow{2}{*}{ Figure description } & \multirow{2}{*}{ Number of load cases/figure } & \multicolumn{4}{|c|}{ Isolation system $\left(\right.$ ratio $\left.^{1}\right)$} & \multirow{2}{*}{ Least efficient ${ }^{2}$} & \multirow{2}{*}{ Most efficient ${ }^{3}$} \\
\hline & & & & LRB & HDR & FPS & RNC & & \\
\hline Line 1 & Figure 12(a) & Long. acceleration & 12 cases & $0 / 4$ & $0 / 8$ & $4 / 0$ & $8 / 0$ & $H D R$ & RNC \\
\hline Line 2 & Figure 12(b) & Trans. acceleration & 12 cases & $0 / 2$ & $0 / 8$ & $4 / 2$ & $8 / 0$ & $H D R$ & RNC \\
\hline Line 3 & Figure 13(a) & Long. displacement & 12 cases & $3 / 3$ & $4 / 1$ & $3 / 8$ & $2 / 0$ & FPS & HDR \\
\hline Line 4 & Figure 13(b) & Trans. displacement & 12 cases & $3 / 4$ & $4 / 0$ & $3 / 8$ & $2 / 0$ & FPS & HDR \\
\hline
\end{tabular}

${ }^{1}$ Ratio of two numbers: the number of load cases per figure in which the isolator was the most relatively efficient among the four types and the number of load cases per figure in which the isolator was the least relatively efficient one.

${ }^{2}$ The least relatively efficient isolation system (among the four types) in the study of the corresponding figure.

${ }^{3}$ The most relatively efficient isolation system (among the four types) in the study of the corresponding figure.

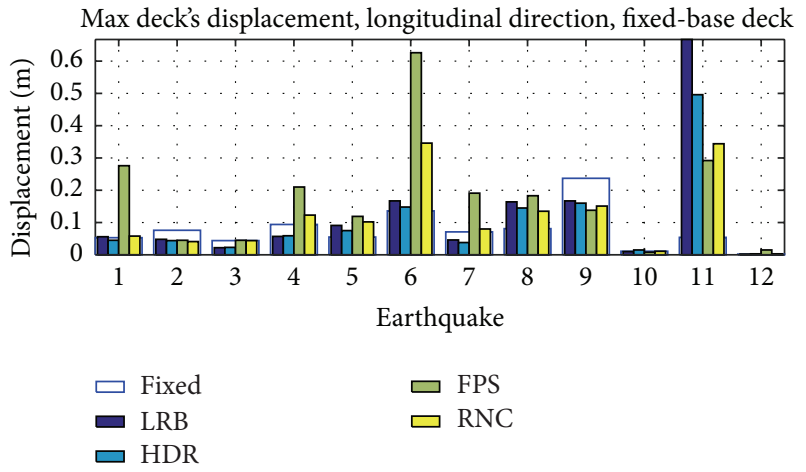

(a)

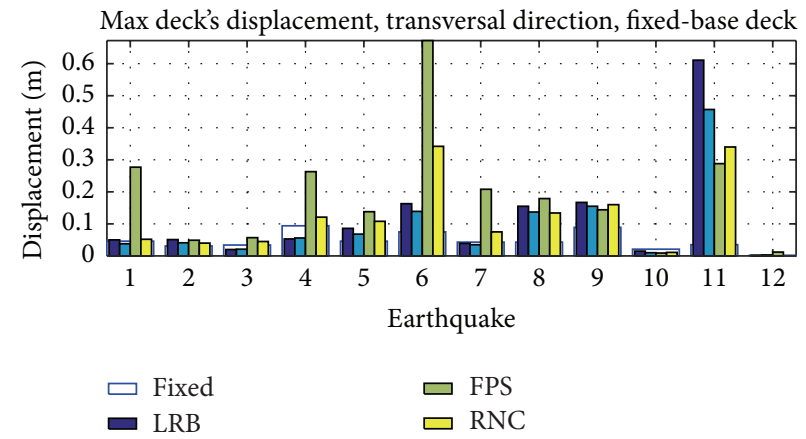

(b)

FIGURE 13: The deck's peak displacements: (a) in longitudinal direction; (b) in transversal direction.

due to Mexico City earthquake). Another observation is related to the close relatively efficient behaviors of both the RNC isolator and the FPS and the similar less relatively efficient behaviors of both LRB and HDR. However, there are visible variations in bearings' efficiencies to permit ranking from relatively best to relatively worst concerning decks acceleration. Table 4 (Lines 1,2) confirms the superior performance of the RNC isolator over the rest of isolation systems, in both longitudinal and transversal directions. The relative efficiency ratio of the RNC isolator is 8 , which is far beyond those of the other isolation bearings in both directions (ratio of two numbers: the number of load cases per figure in which the isolator was the most relatively efficient among the four types and the number of load cases per figure in which the isolator was the least relatively efficient one). Therefore, the RNC has achieved the highest rank based on its relatively best ability to mitigate the deck's peak absolute accelerations. On the other side, the LRB has got the lowest rank along the two directions being the least relatively efficient one.

Figures 13(a) and 13(b) show the price to be accepted as a result of bidirectional mitigation of both max internal forces and peak absolute accelerations of the isolated bridge structure. This price lies in the magnified peak displacement responses of the isolated bridge deck, which is a direct consequence of increasing the lateral flexibility of the bridge bearings. However, although this price of seismic isolation is inevitable, it has to be affordable. This means that the magnified bearing peak displacements have to be within reasonably accepted limits. According to Figures 13(a) and 13(b), the four isolation bearings behave inefficiently under the long-period Kocaeli and Mexico City earthquakes, in addition to the intense near-fault pulse-like Loma Prieta earthquake in both longitudinal and transversal directions, besides the transversal Northridge earthquake. Although the bearings peak displacements are expected to be high, some bearings' relatively odd behaviors were observed considering the twelve excitations together, particularly the FPS and the LRB, in which their lateral peak displacements approached $70.0 \mathrm{~cm}$. The HDR's peak displacement is nearly $50.0 \mathrm{~cm}$, while that of the RNC isolator was found always below $35.0 \mathrm{~cm}$ in its worst case. This certainly highlights the ability of the RNC isolator to achieve the highest mitigation in structural accelerations accompanied by the lowest peak bearing displacement relative to the other isolation types investigated in this study in general. Evaluation of the four bearings types under each individual earthquake leads to the relative efficiency measures listed in Table 4 (Lines 4, 5), which indicates that the HDR has got the highest rank followed by the RNC isolator and then the LRB, while the FPS has got the last rank with a relative efficiency ratio below 0.50 in both longitudinal and transversal directions. It is worth noting that in several cases the peak bearings' displacements were found neutral or even below the fixedbase displacements, mainly under the ground motions having no high velocity/displacement pulses nor long predominant vibration periods. 


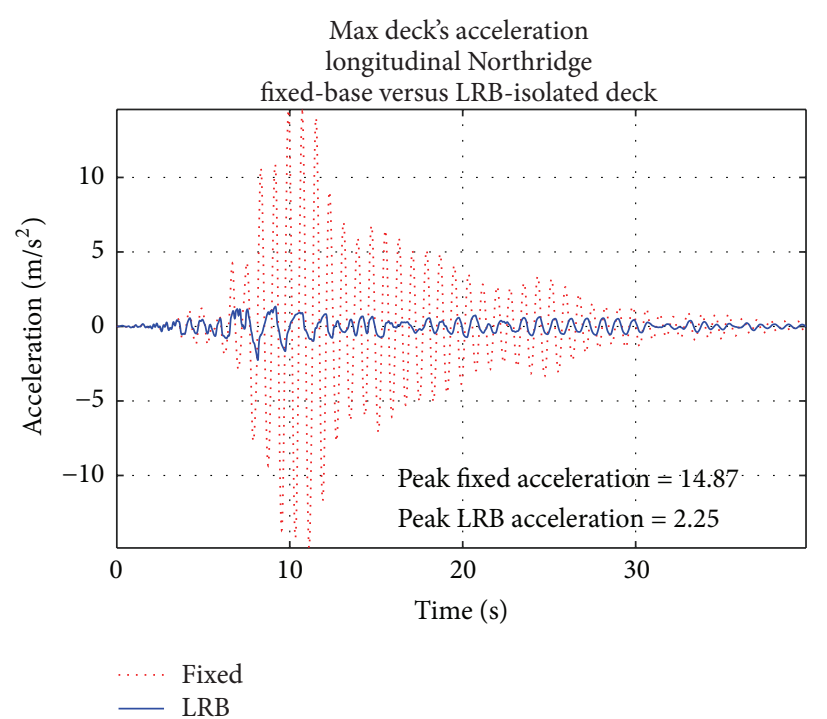

(a)

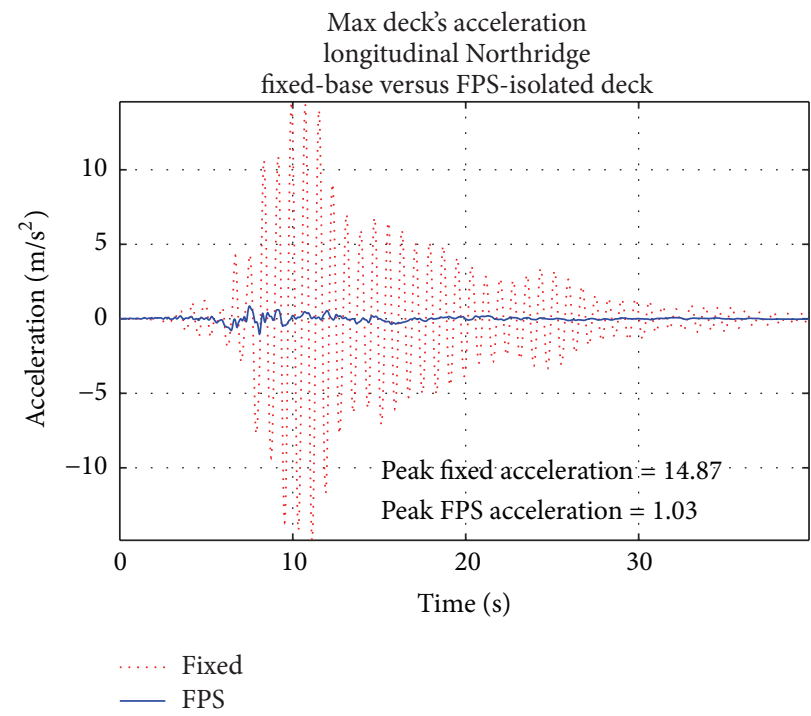

(c)

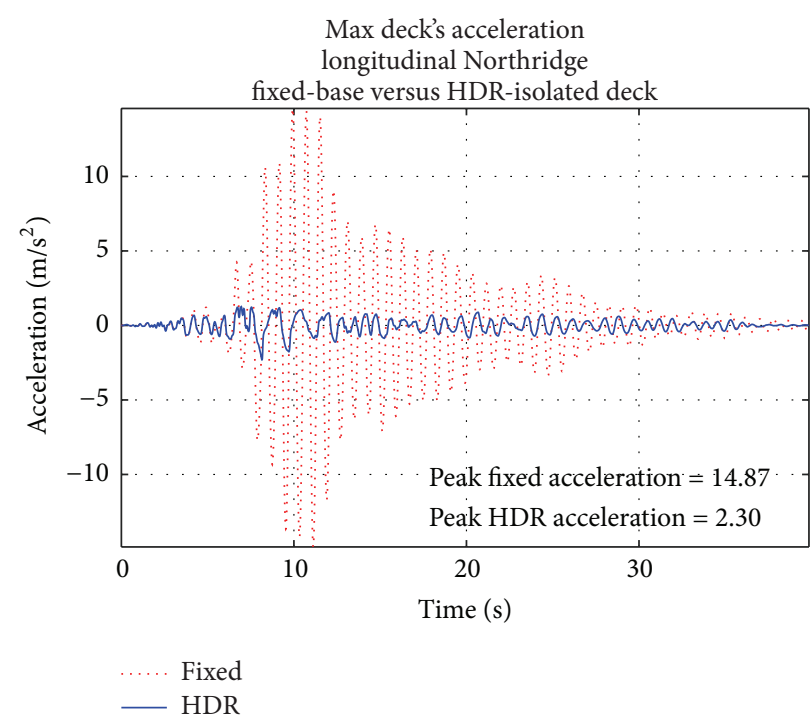

(b)

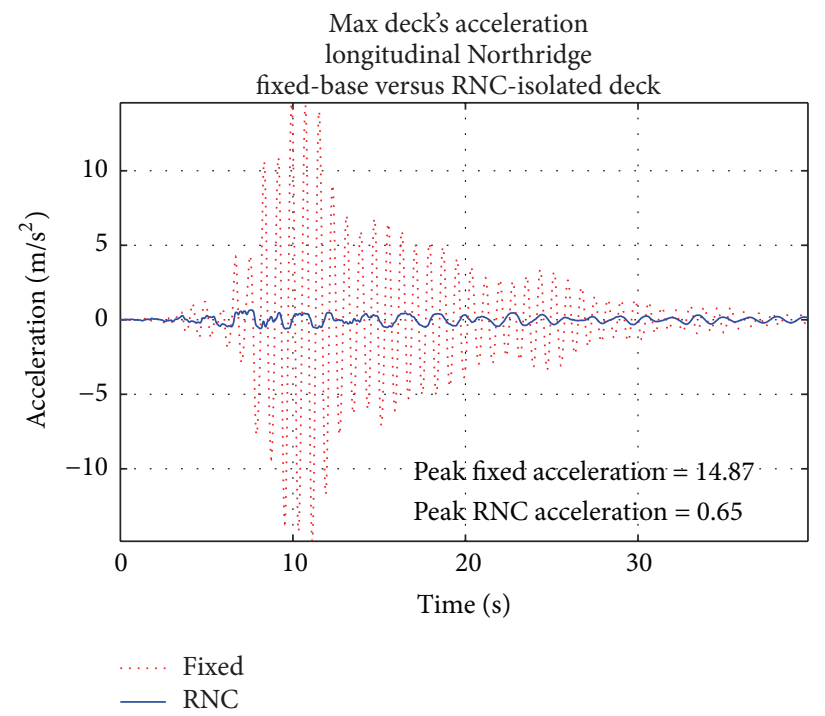

(d)

FIGURE 14: The deck's peak acceleration time histories under longitudinal Northridge earthquake using (a) LRB; (b) HDR; (c) FPS; (d) RNC.

Sample time-history responses of the deck's absolute acceleration responses are shown in Figure 14 under the ground motion causing the maximum fixed-base absolute acceleration, which is the longitudinal Northridge earthquake. It is observed that all the four bearings behave generally in reducing the decks absolute accelerations relative to the fixed-base case. The elastomeric LRB and HDR (Figures 14(a) and 14(b), resp.) produced lower accelerations but with notable frequency compared to the FPS and RNC isolator (Figures 14(c) and 14(d), resp.). However, the RNC isolator provided a deck's acceleration response having a peak value below $65 \%$ of that provided by the FPS. This may indicate that the RNC isolators have provided the relatively best structural behavior among the other isolation bearings in Figure 14.
4.3. Influence of Isolation on the Input Seismic Energies to the Bridge. Energy quantities provide a very useful measure for assessing the isolator performance since they involve all the response variables (displacements, velocity, and accelerations of all degrees of freedom) and therefore represent overall response of the structure. As the energy quantities are scalar, only a single equation for the entire structure can be derived irrespective of the number of degrees of freedom in the structure.

The total absolute energy $E_{i}$ of a base-isolated structure at each time instant can be decomposed in the form by Uang and Bertero [42]:

$$
E_{i}=E_{k}+E_{p}+E_{s}+E_{\xi}+E_{y}
$$




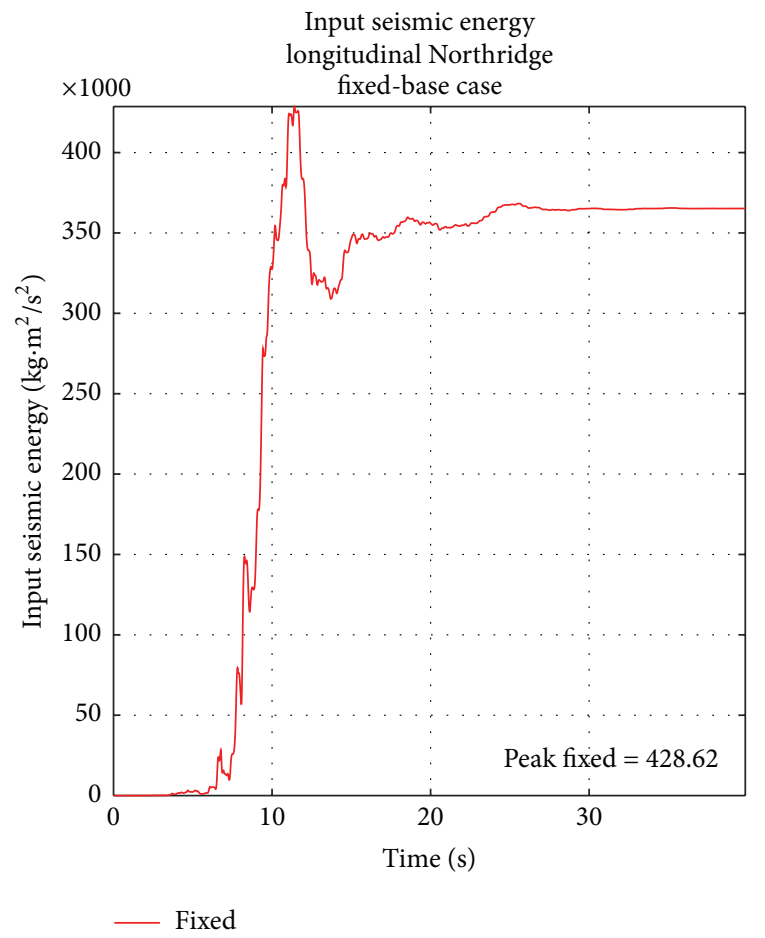

(a)

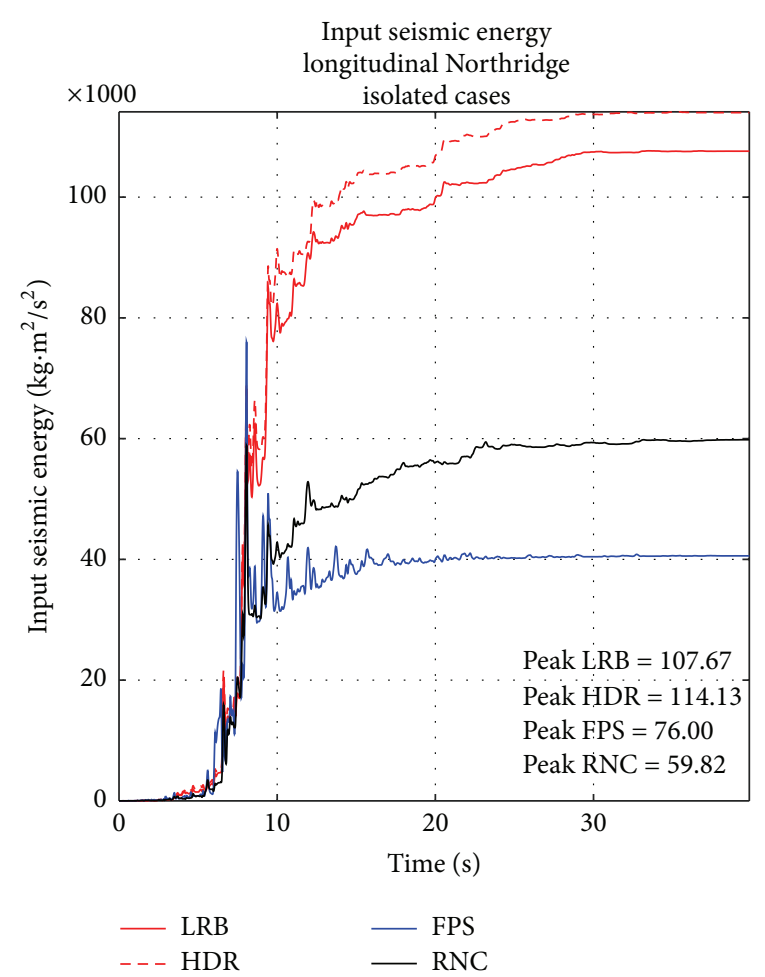

(b)

FIGURE 15: Time history of the input seismic energy due to the longitudinal Northridge earthquake: (a) fixed-base case; (b) isolated cases; $\mathrm{kg}-\mathrm{m}$-sec units.

where $E_{k}, E_{p}$, and $E_{s}$ are kinetic energy, potential energy due to vertical displacement (always zero in this study because the proposed RNC isolator is designed to prevent vertical uplift) of the isolated object during rolling, and strain energy, respectively. These components represent the conservative energy in the system. $E_{\xi}$ and $E_{y}$ are the nonconservative energies due to structural damping and yielding of metallic dampers, respectively.

This section investigates and compares the individual behaviors of the four isolation systems against the fixedbase case regarding the total input seismic energy $E_{i}$ into the bridge structure. A single ground motion is chosen in this section, which is the longitudinal Northridge earthquake. Such ground motion has produced the highest peak ground acceleration in the longitudinal direction, as demonstrated by Figure 12(a) corresponding to earthquake number 9.

Figure 15 shows the time histories of the total input seismic energies into the bridge considering fixed-base deck (Figure 15(a)) and the isolated one using the four isolation systems (Figure 15(b)). Before isolation, the input energy is four times its highest value in the isolated cases (using the HDR). The other systems offer relatively better behaviors, especially the FPS and the RNC isolator that reduced the input seismic energies to 76.0 and 59.82, respectively. The proposed RNC isolator permitted an input energy seven times lower than the fixed-base case. The proposed RNC isolator reduces the dynamic response of the isolated object by filtering the seismic excitations and by dissipating energy through metallic yield dampers, thereby reducing the input energy and seismic demand.

\section{Conclusions}

In this paper, a recently proposed seismic isolation system, named RNC isolator, is presented as an alternative rollingbased isolation bearing for bridge isolation. The bearing's behavior is studied under a set of real and synthetic seismic excitations, applied longitudinally and transversally to a three-span prestressed concrete bridge. Those excitations include near-fault motions, characterized by strong velocity/displacement pulses, as well as pulse-like and long-period excitations. The obtained RNC-isolated deck's responses are related to the corresponding fixed-base responses. In addition, an objective comparative study is conducted considering three wildly used isolation systems at present, which are LRB, HDR, and FPS throughout this paper. Such comparison is intended to highlight the RNC isolator's performance relative to similar isolation bearings.

The results show that seismic isolation is generally efficient in reducing the bridge's internal forces, accelerations, and the input seismic energy transfer, but on the account of amplified bearings' peak displacements. However, it was found that the considered four isolation systems exhibited relatively different performances. Such performances were found inefficient or at least neutral under near-fault motions 
rich in velocity/displacement pulses and those having predominant long-periods. A relative efficiency measure is then proposed for ranking those bearings from relatively best to relatively worst based on their behaviors into the studies performed. It was found that the RNC isolator has achieved the most relatively efficient performance, in this paper, followed by the HDR, FPS, and finally the LRB, which was found to be the least relatively efficient isolation bearing herein. These results confirm, theoretically, that the RNC isolator could be a potentially efficient rolling-based isolation bearing for seismic isolation of bridge structures.

\section{Conflict of Interests}

The authors declare that there is no conflict of interests regarding the publication of this paper.

\section{Acknowledgments}

The authors want to acknowledge the funds received from the Spanish Ministry of Economy and Competitiveness and the FEDER funds from the European Union through the research Project BIA2013-47290-R.

\section{References}

[1] V. Zayas, S. Low, and S. Mahin, "The FPS earthquake resisting system," Experimental Report UCB=EERC 87/01, EERC, University of California, Berkeley, Calif, USA, 1987.

[2] G. W. Housner, L. A. Bergman, T. K. Caughey et al., "Structural control: past, present, and future," Journal of Engineering Mechanics, vol. 123, no. 9, pp. 897-971, 1997.

[3] M. Izumi, "State-of-the-art report: base isolation and passive seismic response control," in Proceedings of the 9th World Conference on Earthquake Engineering, vol. 8, pp. 385-396, Tokyo, Japan, August 1988.

[4] I. G. Buckle and R. L. Mayes, "Seismic isolation history: application and performance-a world review," Earthquake Spectra, vol. 6, no. 2, pp. 161-201, 1990.

[5] J. M. Kelly, "Aseismic base isolation: review and bibliography," Soil Dynamics and Earthquake Engineering, vol. 5, no. 4, pp. 202-216, 1986.

[6] C. Arnold, "Architectural considerations," in The Seismic Design Handbook, F. Naeim, Ed., pp. 275-326, Springer, New York, NY, USA, 2nd edition, 2001.

[7] F. Naeim and J. Kelly, Design of Seismic Isolated StructuresFrom Theory to Practice, John Wiley \& Sons, 1999.

[8] D. Jurukovski and Z. Rakicevic, "Vibration base isolation development and application," in Proceedings of the 10th European Conference on Earthquake Engineering, G. Duma and A. A. Balkema, Eds., pp. 667-676, Rotterdam, The Netherlands, 1995.

[9] K. Staudacher, "Integral earthquake protection of structures IV: full base isolation and seismic mass analogy," Institut für Baustatik und Konstruktion, Bericht 134, Eidgenossische Technische Hochschule, Zurich, Switzerland; Birkhauser, Basel, Switzerland, 1982.

[10] W. Robinson and A. Tucker, "A lead-rubber shear damper," Bulletin of the New Zealand Society for Earthquake Engineering, vol. 10, no. 3, pp. 151-153, 1977.
[11] W. Robinson and A. Tucker, "Test results for lead-rubber bearings for the William M. Clayton building, toe toe bridge, and waiotukupuna bridge," Bulletin of the New Zealand National Society for Earthquake Engineering, vol. 14, no. 1, pp. 21-33, 1983.

[12] R. G. Tyler and W. H. Robinson, "High-strain tests on leadrubber bearings for earthquake loadings," Bulletin of the New Zealand National Society for Earthquake Engineering, vol. 17, no. 2, pp. 90-105, 1984.

[13] C. J. Derham, J. M. Kelly, and A. G. Thomas, "Nonlinear natural rubber bearings for seismic isolation," Nuclear Engineering and Design, vol. 84, no. 3, pp. 417-428, 1985.

[14] N. Mostaghel, M. Hejazi, and J. Tanbakuchi, "Response of sliding structures to harmonic support motion," Earthquake Engineering \& Structural Dynamics, vol. 11, no. 3, pp. 355-366, 1983.

[15] T. Al-Hussaini, V. Zayas, and M. Constantinou, "Seismic isolation of a multi-story frame structureusing spherical sliding isolation systems," Tech. Rep. NCEER-94-0007, National Center of Earthquake Engineering Research, Buffalo, NY, USA, 1994.

[16] P. Murnal and R. Sinha, "Aseismic design of structureequipment systems using variable frequency pendulum isolator," Nuclear Engineering and Design, vol. 231, no. 2, pp. 129-139, 2004.

[17] R. S. Jangid, "Stochastic seismic response of structures isolated by rolling rods," Engineering Structures, vol. 22, no. 8, pp. 937946, 2000.

[18] T.-W. Lin and C.-C. Hone, "Base isolation by free rolling rods under basement," Earthquake Engineering and Structural Dynamics, vol. 22, no. 3, pp. 261-273, 1993.

[19] T.-W. Lin, C.-C. Chern, and C.-C. Hone, "Experimental study of base isolation by free rolling rods," Earthquake Engineering and Structural Dynamics, vol. 24, no. 12, pp. 1645-1650, 1995.

[20] R. S. Jangid and Y. B. Londhe, "Effectiveness of elliptical rolling rods for base isolation," Journal of Structural Engineering, vol. 124, no. 4, pp. 469-472, 1998.

[21] Q. Zhou, X. Lu, Q. Wang, D. Feng, and Q. Yao, "Dynamic analysis on structures base-isolated by a ball system with restoring property," Earthquake Engineering and Structural Dynamics, vol. 27, no. 8, pp. 773-791, 1998.

[22] M. Ismail, An innovative isolation device for aseismic design [Ph.D. thesis], Doctoral Program: Earthquake Engineering and Structural Dynamics, Polytechnic University of Catalonia, Barcelona, Spain, 2009, http://www.tdx.cat/handle/10803/6265.

[23] M. Ismail, J. Rodellar, and F. Ikhouane, "Method for the seismic isolation of a supported object," Patents no. WO2010000897A1, ES20080002043, P200802043, PCT/ES2009/000351, Spanish Office of Patents and Marks, 2008.

[24] M. Ismail, J. Rodellar, G. Carusone, M. Domaneschi, and L. Martinelli, "Characterization, modeling and assessment of Roll$\mathrm{N}$-Cage isolator using the cable-stayed bridge benchmark," Acta Mechanica, vol. 224, no. 3, pp. 525-547, 2013.

[25] M. Ismail, J. Rodellar, and F. Ikhouane, "Performance of structure-equipment systems with a novel roll-n-cage isolation bearing," Computers and Structures, vol. 87, no. 23-24, pp. 16311646, 2009.

[26] M. Ismail, J. Rodellar, and F. Ikhouane, "An innovative isolation bearing for motion-sensitive equipment," Journal of Sound and Vibration, vol. 326, no. 3-5, pp. 503-521, 2009.

[27] M. Ismail, J. Rodellar, and F. Ikhouane, "Seismic protection of low- to moderate-mass buildings using RNC isolator," Structural Control and Health Monitoring, vol. 19, no. 1, pp. 22-42, 2012. 
[28] M. Ismail, J. Rodellar, and F. Ikhouane, "An innovative isolation device for aseismic design," Engineering Structures, vol. 32, no. 4, pp. 1168-1183, 2010.

[29] M. Ismail, J. Rodellar, and F. Ikhouane, "Seismic protection of low- to moderate-mass buildings using RNC isolator," Structural Control and Health Monitoring, vol. 19, no. 1, pp. 22-42, 2012.

[30] M. Ismail, J. R. Casas, and J. Rodellar, "Near-fault isolation of cable-stayed bridges using RNC isolator," Engineering Structures, vol. 56, pp. 327-342, 2013.

[31] M. Ismail and J. Rodellar, "Experimental mechanical characterization of a rolling-based seismic isolation system," in Proceedings of the 6th World Conference on Structural Control and Monitoring (6WCSCM '14), Barcelona, Spain, July 2014.

[32] M. Ismail and J. Casas, "Novel isolation device for protection of cable-stayed bridges against near-fault earthquakes," Journal of Bridge Engineering (ASCE), vol. 19, no. 8, 2014.

[33] D. R. Pant, A. C. Wijeyewickrema, and M. A. ElGawady, "Appropriate viscous damping for nonlinear time-history analysis of base-isolated reinforced concrete buildings," Earthquake Engineering \& Structural Dynamics, vol. 42, no. 15, pp. 23212339, 2013.

[34] AASHTO, LRFD Bridge Design Specifications, US Units, American Association of State Highway and Transportation Officials, 6th edition, 2012.

[35] FEMA, NEHRP Recommended Provisions: Design Examples, Building Seismic Safety Council for the Federal Emergency Management Agency (FEMA) of the Department of Homeland Security, 2006.

[36] S. Nagarajaiah, A. Reinhorn, and M. Constantinou, "Nonlinear dynamic analysis of three-dimensional base isolated structures (3D-basis)," NagarReport NCEER-91-0005, National Center for Earthquake Engineering Research, Buffalo, NY, USA, 1991.

[37] Y. J. Park, Y. K. Wen, and A. H.-S. Ang, "Random vibration of hysteretic systems under bi-directional ground motions," Earthquake Engineering \& Structural Dynamics, vol. 14, no. 4, pp. 543$557,1986$.

[38] Y.-K. Wen, "Method for random vibration of hysteretic systems," Journal of the Engineering Mechanics Division, vol. 102, no. 2, pp. 249-263, 1976.

[39] V. A. Zayas, S. S. Low, and S. A. Mahin, "A simple pendulum technique for achieving seismic isolation," Earthquake Spectra, vol. 6, no. 2, pp. 317-333, 1990.

[40] M. Ismail, "An isolation system for limited seismic gaps in nearfault zones," Earthquake Engineering \& Structural Dynamics, vol. 44, no. 7, pp. 1115-1137, 2015.

[41] M. Ismail, "Inner pounding control of the RNC isolator and its impact on seismic isolation efficiency under near-fault earthquakes," Engineering Structures, vol. 86, pp. 99-121, 2015.

[42] C. Uang and V. V. Bertero, "Evaluation of seismic energy in structures," Earthquake Engineering \& Structural Dynamics, vol. 19, no. 1, pp. 77-90, 1990. 

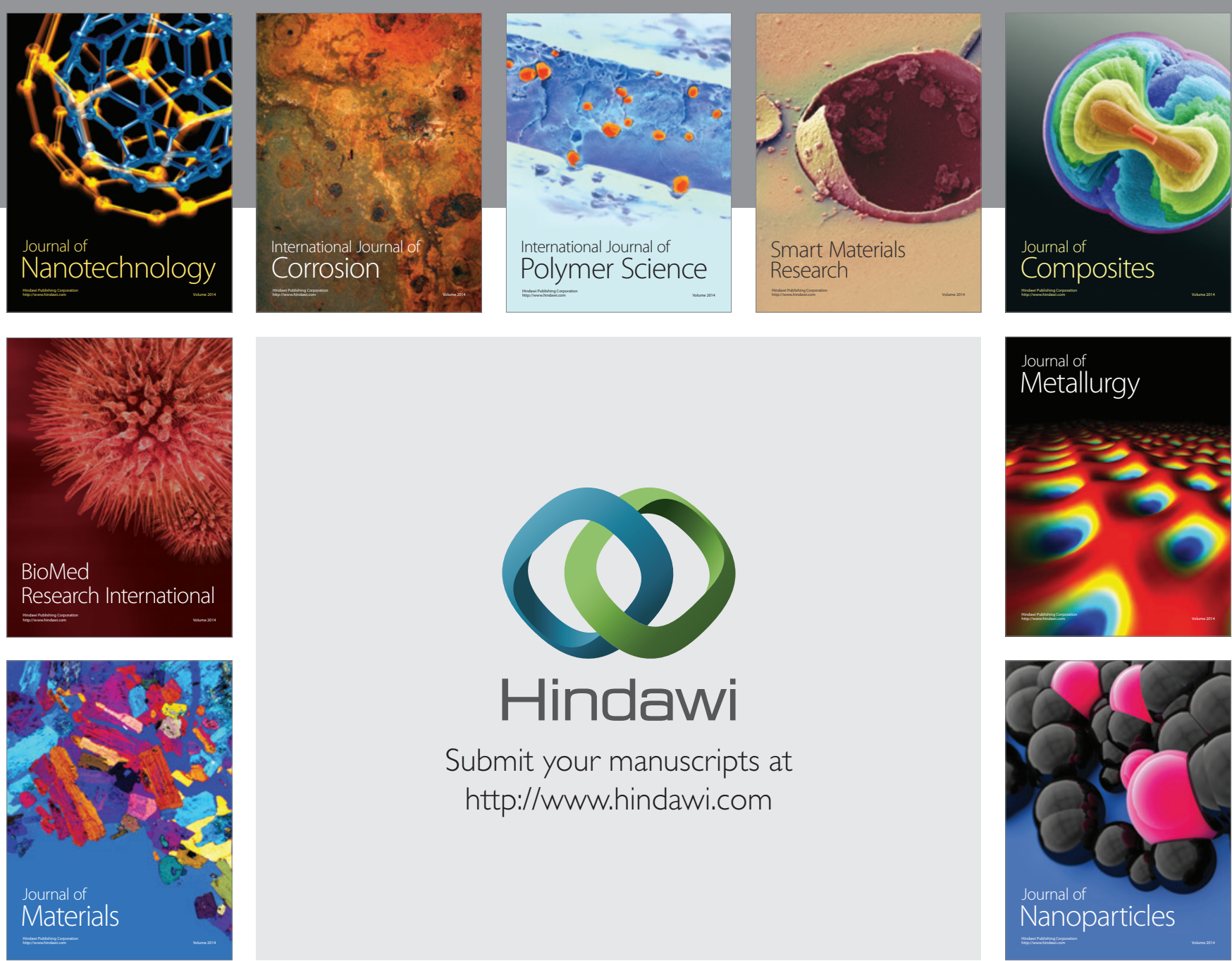

\section{Hindawi}

Submit your manuscripts at

http://www.hindawi.com

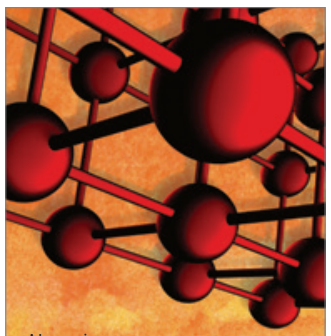

Materials Science and Engineering
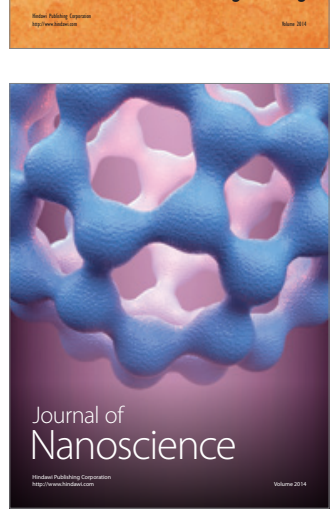
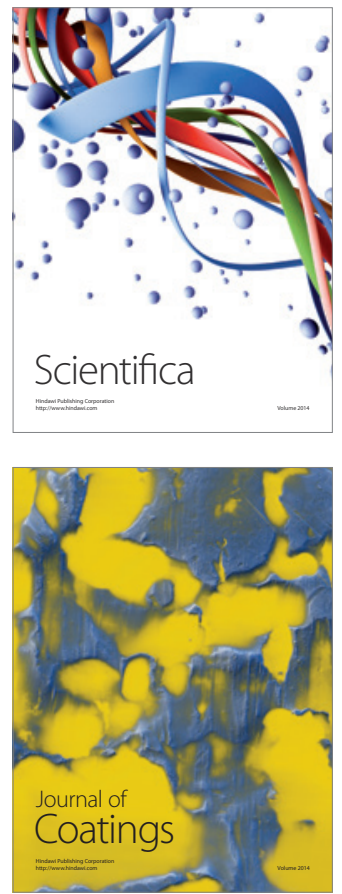
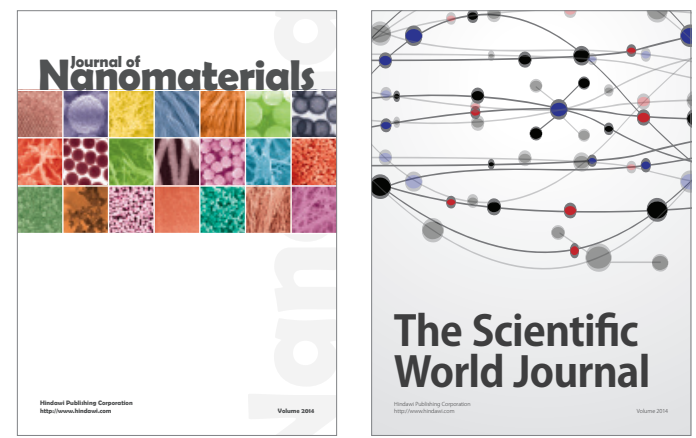

The Scientific World Journal
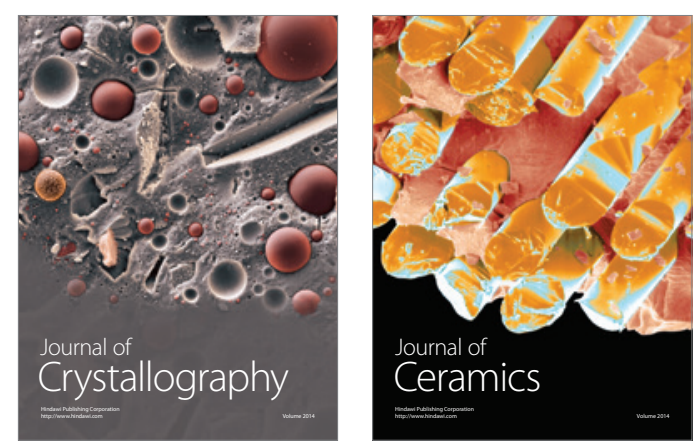
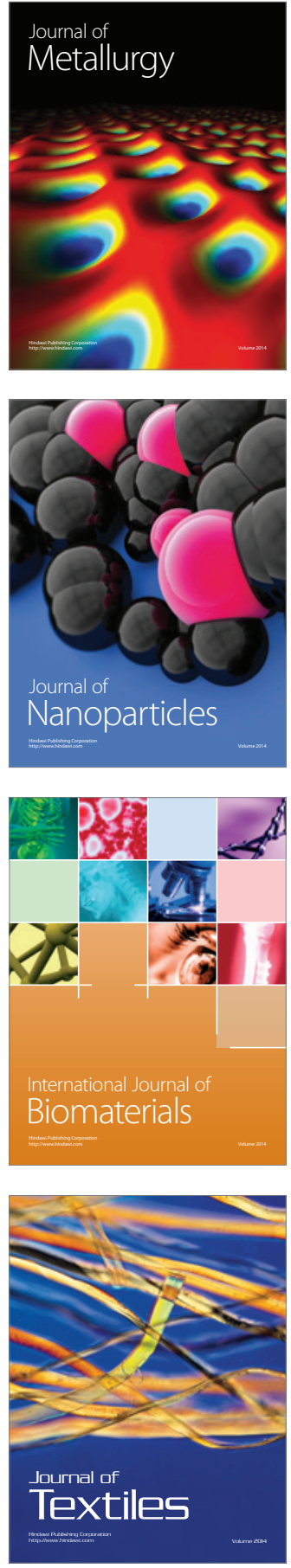